\title{
An Expressed Sequence Tag collection from the male antennae of the Noctuid moth Spodoptera littoralis: a resource for olfactory and pheromone detection research
}

\author{
Fabrice Legeai ${ }^{1}$, Sébastien Malpel ${ }^{2,5}$, Nicolas Montagné2 ${ }^{2}$ Christelle Monsempes ${ }^{2}$, François Cousserans ${ }^{3}$, \\ Christine Merlin ${ }^{2,6}$, Marie-Christine François², Martine Maïbèche-Coisné ${ }^{2}$, Frédérick Gavory ${ }^{4}$, Julie Poulain ${ }^{4}$, \\ Emmanuelle Jacquin-Joly ${ }^{2^{*}}$
}

\begin{abstract}
Background: Nocturnal insects such as moths are ideal models to study the molecular bases of olfaction that they use, among examples, for the detection of mating partners and host plants. Knowing how an odour generates a neuronal signal in insect antennae is crucial for understanding the physiological bases of olfaction, and also could lead to the identification of original targets for the development of olfactory-based control strategies against herbivorous moth pests. Here, we describe an Expressed Sequence Tag (EST) project to characterize the antennal transcriptome of the noctuid pest model, Spodoptera littoralis, and to identify candidate genes involved in odour/ pheromone detection.

Results: By targeting cDNAs from male antennae, we biased gene discovery towards genes potentially involved in male olfaction, including pheromone reception. A total of 20760 ESTs were obtained from a normalized library and were assembled in 9033 unigenes. 6530 were annotated based on BLAST analyses and gene prediction software identified 6738 ORFs. The unigenes were compared to the Bombyx mori proteome and to ESTs derived from Lepidoptera transcriptome projects. We identified a large number of candidate genes involved in odour and pheromone detection and turnover, including 31 candidate chemosensory receptor genes, but also genes potentially involved in olfactory modulation.

Conclusions: Our project has generated a large collection of antennal transcripts from a Lepidoptera. The normalization process, allowing enrichment in low abundant genes, proved to be particularly relevant to identify chemosensory receptors in a species for which no genomic data are available. Our results also suggest that olfactory modulation can take place at the level of the antennae itself. These EST resources will be invaluable for exploring the mechanisms of olfaction and pheromone detection in S. littoralis, and for ultimately identifying original targets to fight against moth herbivorous pests.
\end{abstract}

\section{Background}

Olfaction serves to detect environmental chemical information. Nocturnal insects such as moths appear as ideal models to study the physiology of olfaction, since this sensory modality is essential for their survival and thus

\footnotetext{
* Correspondence: emmanuelle.jacquin@versailles.inra.fr

${ }^{2}$ INRA, UMR-A 1272 INRA-UPMC PISC Physiologie de I'Insecte: Signalisation et

Communication, route de Saint-Cyr, 78026 Versailles Cedex, France

Full list of author information is available at the end of the article
}

highly developed. In particular, the moth pheromone detection system is extremely sensitive: a male can smell and locate a female miles away for mating [1]. It has been for long an established model to study the molecular bases of olfaction [2]. In addition, moths include diverse and important pests of crops, forests and stored products. Olfaction underlies several behaviours critical for crop aggression, including sex pheromone-mediated reproduction, host selection and oviposition [3]. It is
Ciomed Central

() 2011 Legeai et al; licensee BioMed Central Ltd. This is an Open Access article distributed under the terms of the Creative Commons Attribution License (http://creativecommons.org/licenses/by/2.0), which permits unrestricted use, distribution, and reproduction in any medium, provided the original work is properly cited. 
thus an attractive target for pest control. For example, several olfactory-based strategies have been developed to control moth populations, such as mass trapping and mating disruption [4]. Better knowledge on the molecular mechanisms by which an odour generates a neuronal signal could lead to the identification of targets for the development of new safe control strategies.

The olfactory signals are detected by the antennae, the peripheral olfactory organs, where they are transformed in an electrical signal that will be further integrated in the central nervous system. Located on the head, the antennae carry thousands of innervated olfactory structures, the sensilla, which house the olfactory receptor neurons. Within these sensilla, odour recognition relies on the expression of a diversity of olfactory genes involved in different steps (reviewed in [5]). First, volatile odours are bound by odorant-binding proteins (OBPs) in order to cross the aqueous sensillum lymph that embeds the olfactory neuron dendrites. The OBP family notably includes two sub-families: the pheromone-binding proteins (PBPs), thought to transport pheromone molecules, and the general odorant-binding proteins (GOBPs), thought to transport general odorants such as plant volatiles [6,7]. Many other soluble secreted proteins are also found in abundance within the sensillum lymph, examples are the so-called chemosensory proteins (CSPs), the antennal binding proteins $\mathrm{X}$ (ABPX) and the sensory appendage proteins (SAPs) [8], but their role in olfaction remains elusive. After crossing the lymph, odorant molecules interact with olfactory receptors (ORs, called pheromone receptors or PRs when ligands are pheromones) located in the dendritic membrane of receptor neurons (reviewed in [9]). The chemical signal is then transformed into an electric signal that will be transmitted to the brain. Sensory neuron membrane proteins (SNMPs), located in the dendritic membrane of pheromone sensitive neurons $[7,10]$, are thought to trigger ligand delivery to the receptor [11]. Signal termination may then be ensured by specific enzymes, the odorant-degrading enzymes (ODEs, called pheromone-degrading enzymes or PDEs when substrates consist of pheromones) (reviewed in [7]). Although we still lack a consensus on the exact function of each protein family, the occurrence of a large diversity within these families suggests they participate in the specificity of odour recognition [2]. The combinatorial expression of these proteins within a sensillum may ensure the specificity and the sensitivity of the olfactory reception, defining the functional phenotypes of olfactory receptor neurons.

Complete or partial repertoires of putative olfactory genes have been established in insect species with an available sequenced genome. In other species for which no genomic data are yet available, such as crop pest moths, we still lack a global view of the olfactory genes. Homology-based cloning strategies led to the identification of conserved genes, such as OBPs [12], but failed to reliably identify divergent genes, in particular ORs. Insect ORs constitute an atypical family of seven transmembrane domain receptors exhibiting a pronounced intra - as well as inter-specific sequence diversity. As a result, OR repertoires have been established using the complete or partial genome databases of, among examples, the dipterans Drosophila melanogaster [13-15] and Anopheles gambiae [16], the hymenopterans Apis mellifera [17] and Nasonia vitripennis [18], the coleopteran Tribolium castaneum [19] and the lepidopteran B. mori $[20,21]$. In other Lepidoptera, only few ORs and PRs have been identified to date [22-27]. Among them, one atypical subtype of ORs, defining the so-called D. melanogaster OR83b orthologue family, is required for the functionality of the other ORs [28,29]. This subtype is highly conserved among insects and orthologues have been identified in numerous species, including a variety of moths [30,31]. The identification of additional moth ORs and PRs is thus challenging. This will provide information on the evolution and diversification of this receptor family in this biodiverse group of insects and, in a context of plant protection, ORs appear as good targets for the design of molecules capable to interfere with the ligand and thus the receptor response and the associated insect behaviour.

Expressed Sequence Tag (EST) sequencing strategies are efficient in identifying a large number of genes expressed in a particular tissue, thus providing information on the physiological properties of this specific tissue. Such approaches are particularly relevant when no genomic data are available for the target species. EST collections are now established for various tissues in several Lepidoptera species, especially in B. mori, the only Lepidoptera for which the genome has been sequenced [32]. However, only two EST strategies have been previously engaged on antennae. In 1999, Robertson et al [33] sequenced 300 ESTs from Manduca sexta antennae and identified a variety of candidate OBPs, but no ORs. In 2008, Jordan et al [34] sequenced 5739 ESTs from the antennae of the tortricid, Epiphyas postvittana, whose analysis revealed members of families implicated in odorant and pheromone binding (PBPs, GOBPs, ABPXs, CSPs) and turnover (putative ODEs). Only three genes encoding putative ORs were found, including one encoding an orthologue of the non-canonical odorant receptor OR83b from Drosophila.

In view of these difficulties in identifying ORs, we combined high-throughput sequencing and normalization of a cDNA library, prepared from the antennae of the cotton leafworm Spodoptera littoralis. This polyphagous noctuid species is one of the major pests of cotton, 
and much is known about its olfaction, thanks to previous behavioural and electrophysiological investigations: the sex pheromone, plant volatiles activating olfactory neurons, and various functional types of olfactory sensilla have been characterized [35]. S. littoralis thus appears particularly well-suited to establish the molecular bases of olfactory and pheromone reception in a crop pest from the noctuid family, which groups some of the most aggressive herbivorous pests.

In this paper, we report the analysis and annotation of 20760 ESTs obtained from S. littoralis male antennae. First, this allowed us to establish the use of transcriptome sequencing to identify putative olfactory genes, and among them chemosensory receptor-encoding genes. We report on the identification of 31 candidate olfactory/gustatory receptor genes in a species for which no genomic data are available. Second, we provide evidence that the antennae express different non olfactory genes possibly involved in processes such as defense, plasticity and circadian rhythms. These EST resources will be invaluable for exploring the mechanism of olfaction and pheromone detection, but also other antennal processes, in a pest model species.

\section{Results and discussion}

\section{EST statistics and unigene prediction}

A total of 20760 ESTs (mean length: $958.1 \mathrm{bp}$, median length: $820 \mathrm{bp}$, max length: $1525 \mathrm{bp}$, min length: $40 \mathrm{bp}$, table 1) were obtained from male antennae of S. littoralis. A first batch of 2211 sequences, obtained by Genome-express (Grenoble, France), has been deposited in the GenBank database [GenBank:GW824594GW826804]. A second batch of 18549 ESTs, sequenced by the Genoscope (Evry, France), has been deposited in the European Molecular Biology Laboratory (EMBL) [EMBL:FQ014236-FQ032656,] and GenBank [GenBank: HO118288-HO118415]. Full description of all ESTs is available in additional file 1 . The ESTs were processed and assembled. 14385 ESTs (69.3\%, mean length: 929.5 bp, median length: $804 \mathrm{bp}$ ) were assembled into 2705 contigs, 6328 sequences corresponded to singletons and 47 were removed due to vector contamination. The contigs have been submitted to INSDC into the TSA division [EZ980986-EZ983690]. All together, singletons and contigs were merged into a set of 9033 unigenes that putatively represent different transcripts (mean length: $1095.2 \mathrm{bp}$, median length: $1198 \mathrm{bp}$, max length: 3609 bp, min length: $40 \mathrm{bp}$, table 1). Full description of the unigenes is available in additional file 2. On average, each contig was assembled from 5.32 ESTs. 6328 $(\sim 70 \%)$ of the unigenes were singletons, 899 (33.23\%) of contig sequences had two ESTs, 481 (17.78\%) had three ESTs, and 275 (10.20\%) had more than 10 ESTs. It has to be pointed out that we did only 5 ' end sequencing that, together with splice variants, polymorphism or reverse transcriptase errors, may have led to underassembly and thus over-estimation of unigene counts. Examples of such under-assembly, revealed by manual $\mathrm{OBP}$ and $\mathrm{OR}$ analyses, are discussed later.

\section{Identification of putative ORFs}

Among the 9033 unigenes, 6738 presented a coding region (74.6\%, mean length: 215.14 aa, median length: 221 aa, max length: 922 aa, min length: 30 aa, table 1). Protein sequences translated from the predicted open reading frame (ORF) set were compared to the nonredundant protein database (NR) and to the D. melanogaster and B. mori complete proteomes (e-value cut off: 1e-5) (Figure 1). Most of the sequences (90\%) translated from predicted ORFs, showed similarity to known proteins. 678 ORFs presented no similarity at all. The 972 protein sequences having no similarity with the $B$. mori proteome were further compared to the $B$. mori genome using TBLASTX (e-value cut off: 1e-20), since the B. mori protein prediction available in SilkDB may have missed some genes. 713 remaining S. littoralis protein sequences had no similarity with any $B$. mori gene. 50 were classified in a gene ontology term and were analyzed using BLAST2GO (Additional file 3). Interestingly, we found enrichment in putative proteins involved

Table 1 Data summary

\begin{tabular}{lllllll}
\hline & $\begin{array}{l}\text { Counts } \\
\text { (total } \mathbf{n b})\end{array}$ & $\begin{array}{l}\text { Min. length } \\
\text { (bp/aa) }\end{array}$ & $\begin{array}{l}\text { Average length } \\
\text { (bp/aa) }\end{array}$ & $\begin{array}{l}\text { Max length } \\
\text { (bp/aa) }\end{array}$ & $\begin{array}{l}\text { Median lenght } \\
\text { (bp/aa) }\end{array}$ & Accession numbers \\
\hline All ESTs & 20760 & 40 & 958.1 & 1525 & 820 & $\begin{array}{l}\text { FQ0142366-FQ032656 } \\
\text { GW824594-GW826804 } \\
\text { HO118288-HO118415 }\end{array}$ \\
\hline Singletons & 6328 & 40 & 1029.5 & 1500 & 1172 & EZ980986-EZ983690 \\
\hline Contigs & 2705 & 40 & 1277.1 & 3609 & 1290 & 1198 \\
\hline All unigenes & 9033 & 40 & 1095.2 & 3609 & 1217 & \\
\hline Annotated unigenes* & 6530 & 40 & 1127.9 & 3609 & 221 & \\
\hline Predicted peptides & 6738 & 30 & 215.14 & 922 & & \\
\hline
\end{tabular}

*unigenes with a significant match against nr, Drosophila melanogaster proteome or Bombyx mori transcripts. 


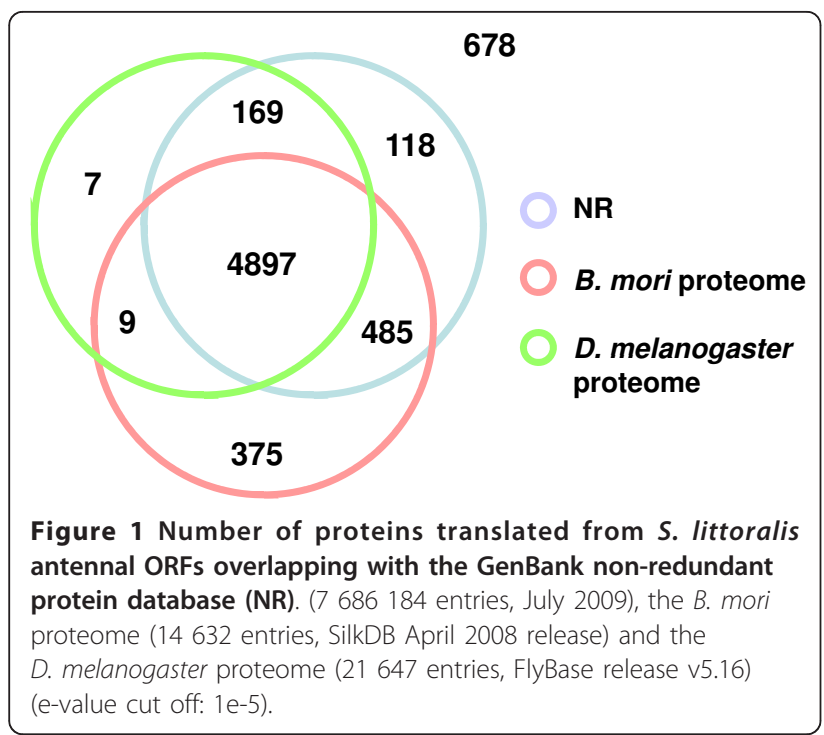

in defense response to bacteria (FDR: 7,21E-004), antifungal humoral response (2,04E-006), xenobiotic metabolism processes $(8,08 \mathrm{E}-006)$ and interaction between organisms (1,56E-007). An enrichment in defenserelated objects was recently observed by Vogel et al [36] in the transcriptome of the noctuid Heliothis virescens pheromone glands, when compared to that of B. mori.

The 678 sequences presenting no similarity with any known protein were analyzed using Interproscan [37] (Additional file 4). Interestingly, a sequence of this set presented a $\mathrm{PBP} / \mathrm{GOBP}$ protein domain and appeared as a new original candidate OBP, in addition to the others we discovered (see paragraph below).

\section{Specificity analysis using ESTs}

The unigenes were compared to all published ESTs from other Lepidoptera retrieved from NCBI's dbEST (550 623 entries, June 2009) using BLASTN (Figure 2). 3831 sequences $(42.4 \%)$ gave no similarity to any other ESTs (e-value cut off: 1e-10). The size of these sequences (mean size: $1041.7 \mathrm{bp}$ ) is significantly shorter ( $\mathrm{t}$-test, $\mathrm{t}=354.283, \mathrm{df}=10402, \mathrm{p}$ value $<2.2 \mathrm{e}-16)$ than the size of the 5202 sequences matching with other lepidopteran ESTs (mean size $=1134.7$ bp). $1448(37.8 \%)$ of the 3831 sequences without EST match had no predicted ORF, which is also significantly higher than the $847(16.3 \%)$ observed in the set of 5202 sequences with an EST match (Chi2, X-squared $=537.7, \mathrm{df}=1, \mathrm{p}$-value $<2.2 \mathrm{e}-16$ ) (Figure 2). The assigned 1448 ORFs, which have no match in other EST libraries, correspond to genes that were never isolated from transcriptomic approaches before and likely represent antennal specific transcripts. The 849 ORFs without EST match but with a gene ontology (GO) classification were compared to the 2766 ORFs with at least one EST match and a GO

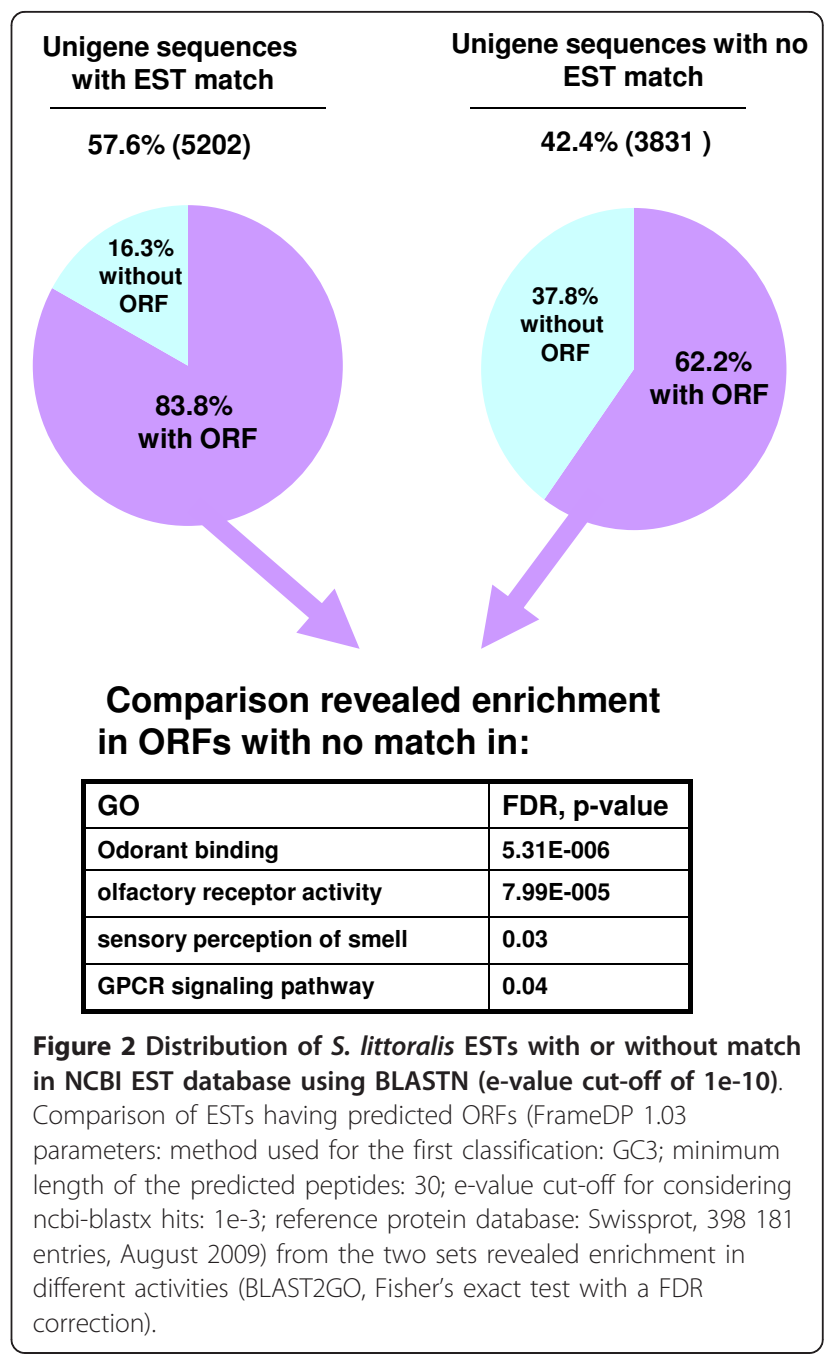

classification (Additional file 5). This comparison should reflect gene enrichment in the antennal transcriptome. Interestingly, the set showed enrichment in odorant binding, olfactory receptor activity, sensory perception of smell and G-protein coupled receptor signalling pathway, in correlation with the sensory function of this organ.

\section{Gene identification and functional annotation}

Figure 3 illustrates the distribution of the $S$. littoralis unigene set in GO terms, compared to the distribution of all $B$. mori genes having GO terms (retrieved from http://www.silkdb.org/cgi-bin/silkgo/index.pl). Among the 6738 S. littoralis ORFs, 3619 corresponded to at least one GO term. 3072 were assigned to a molecular function (45.6\%), 2586 to putative biological processes (38.4\%), and 2282 to a cellular component (33.9\%). In the molecular function category, binding and catalytic activities were the most abundant and enriched compared to the $B$. mori genome, in correlation with the 


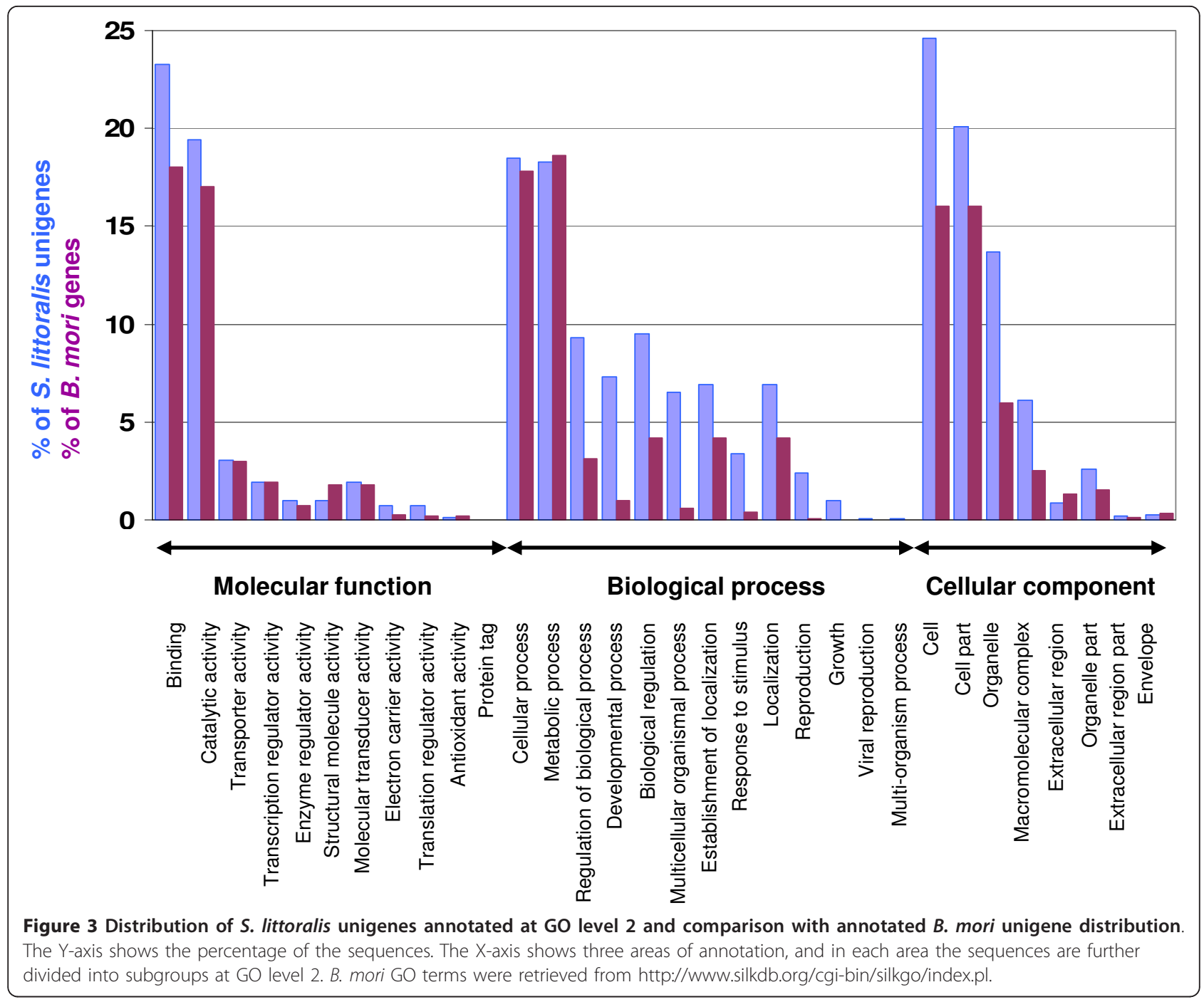

results obtained through the specific analyses using available ESTs (see previous paragraph). In the biological process terms, cellular and metabolic processes were the most represented, the other terms being more abundant than in the B. mori genome. In the cellular component terms, cell, cell part and organelle were the most abundant and over represented compared to the B. mori genome.

Identification of putative enzymes and secretory proteins Enzymes are supposed to be abundantly expressed in antennae, as part of the signal termination pathway, but may also participate in neuron protection by xenobiotic degradation [38]. A total of 941 S. littoralis ORFs were classified in enzymatic categories using BLAST2GO. In addition to this large analysis, we searched the $S$. littoralis ORF BLASTP results for enzymes expressed in the antennae, with specific key-words corresponding to putative ODEs: carboxylesterase (CXE), glutathione
S-transferase and cytochrome P450, which led to the list of 71 unigenes reported in table 2. We found 18 ORFs presenting significant similarities with CXEs. Among the insect putative ODEs, the CXE family is the most studied, and esterase activities were identified in several species that use acetates in their sex pheromone blends [38-42]. In a previous search for CXEs expressed in the antennae of $S$. littoralis (a species that mainly uses acetates as pheromone components) we were able to identify 19 putative esterases [43], among which two were specifically expressed in the antennae. Further comparison of these two sets of esterases will complete the putative CXE repertoire in S. littoralis antennae. Other enzyme families proposed to participate in olfactory signal turnover include glutathione S-transferases and cytochrome P450, which can modify odorants to produce odour-inactive compounds [7]. We found 14 and 39 ORFs presenting high similarities with glutathione S-transferases and cytochrome P450, respectively. Our 
Table 2 Accession numbers of $S$. littoralis unigenes annotated as encoding Carboxylesterases (CXEs), Glutathione-S-transferases (GSTs), Cytochrome P450 (CYPs) and related enzymes

\begin{tabular}{|c|c|c|c|}
\hline CXEs & GSTs & CYPs & NADPH CYP reductases \\
\hline EZ981801 & FQ023109 & FQ024248 & EZ980988 \\
\hline FQ022303 & FQ020799 & EZ981137 & FQ017461 \\
\hline EZ982197 & FQ022743 & FQ021196 & \\
\hline FQ019114 & FQ019149 & FQ021671 & \\
\hline EZ983083 & GW825667 & FQ019544 & \\
\hline FQ022545 & FQ017387 & HO118356 & \\
\hline EZ983369 & EZ982764 & EZ982595 & \\
\hline FQ023061 & HO118396 & EZ981458 & \\
\hline FQ015927 & FQ027411 & EZ981571 & \\
\hline FQ022747 & FQ018875 & FQ018915 & \\
\hline FQ020250 & GW826417 & EZ981789 & \\
\hline EZ982323 & FQ019239 & EZ981875 & \\
\hline EZ982624 & EZ981154 & EZ983482 & \\
\hline EZ982921 & EZ982089 & FQ015142 & \\
\hline EZ983638 & & FQ014678 & \\
\hline EZ983598 & & GW825436 & \\
\hline FQ022223 & & FQ022752 & \\
\hline \multirow[t]{20}{*}{ FQ020727 } & & FQ028570 & \\
\hline & & FQ015778 & \\
\hline & & EZ982503 & \\
\hline & & FQ020310 & \\
\hline & & FQ018184 & \\
\hline & & EZ981487 & \\
\hline & & FQ018799 & \\
\hline & & EZ982387 & \\
\hline & & EZ982392 & \\
\hline & & EZ983317 & \\
\hline & & EZ983029 & \\
\hline & & EZ982194 & \\
\hline & & EZ982440 & \\
\hline & & EZ981393 & \\
\hline & & EZ982843 & \\
\hline & & EZ981535 & \\
\hline & & EZ983216 & \\
\hline & & FQ028959 & \\
\hline & & EZ982050 & \\
\hline & & EZ983461 & \\
\hline
\end{tabular}

analysis confirms that antennae are a hot-spot for enzymatic activities, as suggested by the previous analysis of antennal ESTs from E. postvitana [34]. The role of all these enzymes in olfaction remains to be studied, since these enzymes could also be involved in other processes, such as xenobiotic degradation [38].

The olfactory process within the antennae is thought to be triggered by a large family of proteins, the socalled OBPs, secreted in the sensillum lymph [8]. We thus found it relevant to search for secretory proteins through SignalP [44] in all the translated S. littoralis ORFs. A total of 636 translated ORFs (84.1\%) were predicted to contain a signal peptide, among which 565 $(88.8 \%)$ have matches with known proteins in the NR protein database. Among them, candidate binding proteins were found. A complete analysis of candidate OBPs found in the S. littoralis ESTs is detailed in the paragraph below. The remaining $11.2 \%$ of the putative S. littoralis secretory proteins did not share significant similarity with known proteins.

\section{Identification of putative S. littoralis odorant-binding proteins}

35 putative S. littoralis OBP (SlitOBP) and 12 putative CSP (SlitCSP) fragments were first extracted from the unigenes by scanning the Interproscan result for the Interpro accession IPR006170, TBLASTN search in NR, and specific TBLASTN search among the ESTs with the B. mori OBP [45] and CSP [46] (further defined as BmorOBP and BmorCSP) complete repertoires as queries. After a detailed analysis of sequence alignments, several contigs and/or singletons that were not automatically assembled were considered to encode a same putative protein (Table 3). In some cases, pairwise alignments revealed a few nucleotide mismatches, which possibly mirror polymorphism or enzyme errors in the cDNA synthesis process (eg EZ982609/FQ016892). In other cases, alignments revealed the presence of large inserts within nucleotide sequences, likely corresponding to unspliced introns. GT splice donor sites were found at the beginning of these inserts and their location appeared to be similar to intron locations described in B. mori OBP and CSP genes [45,46] (eg EZ981038/ EZ982027 for OBPs; EZ983373/GW825922 for CSPs). In total, we annotated 17 SlitOBPs (including six ABPs) and nine SlitCSPs (including one SAP) listed in table 3. Some SlitOBP/CSP unigenes were incomplete at their 5' ends and the corresponding proteins missed the signal peptide (Table 3).

Interestingly, using Interproscan, a new putative OBP type was found (FQ020630) that presented no sequence identity with any known insect OBPs (only $27 \%$ identity with its BLASTX best hit D. melanogaster OBP59a, evalue 0.27 , unexpected for insect OBPs). The deduced encoded protein seemed to be complete (with start and stop codons) but SignalP analyses did not reveal the occurrence of a signal peptide, suggesting that this protein is not secreted or that we missed its $\mathrm{N}$-terminal part. This latter hypothesis is supported by the fact that the amino acid sequence contains only five cysteine residues, one less than usually observed in insect OBPs. Alternatively, this sequence could encode a protein belonging to the Takeout or juvenile hormone-binding protein families, since these protein families also bind 
Table 3 List of S. littoralis unigenes putatively involved in olfactory binding

\begin{tabular}{|c|c|c|c|c|c|c|c|}
\hline Unigene reference & $\begin{array}{l}\text { EST } \\
\mathrm{nb}\end{array}$ & Frame & $\begin{array}{l}\text { ORF } \\
\text { size } \\
\text { (aa) }\end{array}$ & $\begin{array}{l}\text { Blastx best hit } \\
\text { Reference/Sequence name/species }\end{array}$ & E value & Identities & $\begin{array}{l}\text { Signal } \\
\text { peptide }\end{array}$ \\
\hline \multicolumn{8}{|l|}{ Pheromone-binding proteins } \\
\hline EZ981038 (EZ982027) & 2 & +3 & 102 & $\begin{array}{l}\text { gb|AAZ22339.1|pheromone binding protein } 2 \\
\text { [Spodoptera litura] }\end{array}$ & $3 e-41$ & $99 \%$ & YES \\
\hline EZ983456 (GW825701) & 2 & +1 & 163 & $\begin{array}{l}\text { gb|AAO16091.1|pheromone binding protein } 3 \\
\text { [Helicoverpa armigera] }\end{array}$ & $3 e-76$ & $83 \%$ & YES \\
\hline EZ982949 (FQ021292) & 95 & -3 & 164 & $\begin{array}{l}\text { gb|ABQ84981.1|pheromone-binding protein } 1 \\
\text { [Spodoptera littoralis] }\end{array}$ & $1 e-91$ & $100 \%$ & YES \\
\hline \multicolumn{8}{|l|}{ General odorant-binding proteins } \\
\hline EZ981811 (EZ982114) & 8 & +2 & 151 & $\begin{array}{l}\text { gb|ABM54824.1/general odorant-binding } \\
\text { protein GOBP2 [Spodoptera litura] }\end{array}$ & $2 e-84$ & $96 \%$ & YES \\
\hline EZ982647 (FQ018693) & 8 & -1 & 163 & $\begin{array}{l}\text { gb|ABM54823.1/general odorant-binding } \\
\text { protein GOBP1 [Spodoptera litura] }\end{array}$ & $1 e-81$ & $97 \%$ & YES \\
\hline \multicolumn{8}{|l|}{ Other odorant-binding proteins } \\
\hline $\begin{array}{l}\text { EZ983297 (EZ982153, FQ030234, } \\
\text { FQ024265, FQ029312) }\end{array}$ & 9 & +3 & 147 & $\begin{array}{l}\text { emb|CAC33574.1|antennal binding protein } \\
\text { [Heliothis virescens] }\end{array}$ & $6 e-54$ & $72 \%$ & YES \\
\hline EZ983149 & 2 & +3 & 142 & $\begin{array}{l}\text { gb|AAL60416.1|AF393491_ lantennal binding } \\
\text { protein } 2 \text { [Manduca sexta] }\end{array}$ & $5 e-53$ & $65 \%$ & YES \\
\hline EZ981335 (FQ017058) & 140 & -1 & 137 & $\begin{array}{l}\text { emb|CAA05508.1|antennal binding protein } \mathrm{X} \\
\text { [Heliothis virescens] }\end{array}$ & $4 e-53$ & $92 \%$ & YES \\
\hline FQ026764 (FQ031480, HO118380) & 1 & +3 & 141 & $\begin{array}{l}\text { gb|AAL60413.1|AF393488_1antennal binding } \\
\text { protein } 3 \text { [Manduca sexta] }\end{array}$ & $1 e-52$ & $74 \%$ & YES \\
\hline FQ019778 & 1 & +2 & 129 & $\begin{array}{l}\text { gb|AAL60425.1|AF393500_ lantennal binding } \\
\text { protein } 7 \text { [Manduca sexta] }\end{array}$ & $1 e-30$ & $57 \%$ & YES \\
\hline EZ981091 (FQ019778, FQ018991) & 2 & +1 & 147 & $\begin{array}{l}\text { gb|AAX98168.1|pheromone binding protein } 4 \\
\text { [Spodoptera frugiperda] }\end{array}$ & $1 e-72$ & $92 \%$ & YES \\
\hline FQ020630 & 1 & +3 & 174 & $\begin{array}{l}\text { gb|AAO41344.1|Odorant-binding protein 59a } \\
\text { [Drosophila melanogaster] }\end{array}$ & 0.27 & $27 \%$ & NO \\
\hline FQ021259 (FQ018920, FQ015705) & 1 & +2 & 184 & $\begin{array}{l}\text { emb|CAR85645.1|odorant-binding protein } 4 \\
\text { [Myzus persicae] }\end{array}$ & $2 e-34$ & $44 \%$ & YES \\
\hline FQ021928 & 1 & +1 & 62 & $\begin{array}{l}\text { reflNP_001140187.1/odorant-binding protein } 3 \\
\text { [Bombyx mori] }\end{array}$ & $3 e-10$ & $53 \%$ & NO \\
\hline FQ021918 & 1 & +3 & 75 & $\begin{array}{l}\text { ref|NP_001140191.1|odorant-binding protein } 7 \\
\text { [Bombyx mori] }\end{array}$ & $1 e-18$ & $64 \%$ & NO \\
\hline FQ014244 & 1 & +3 & 239 & $\begin{array}{l}\text { dbj|BAH79158.1|odorant binding protein } \\
\text { [Bombyx mori] }\end{array}$ & $2 e-58$ & $49 \%$ & YES \\
\hline EZ983259 (FQ026546, FQ020478) & 31 & +3 & 252 & $\begin{array}{l}\text { dbj|BAH79159.1|odorant binding protein } \\
\text { [Bombyx mori] }\end{array}$ & $1 e-93$ & $60 \%$ & YES \\
\hline \multicolumn{8}{|l|}{ ChemoSensory Proteins } \\
\hline FQ024845 (FQ020519) & 1 & +2 & 113 & $\begin{array}{l}\text { gb|AAK14793.1|sensory appendage protein- } \\
\text { like protein [Mamestra brassicae] }\end{array}$ & $1 e-30$ & $67 \%$ & YES \\
\hline EZ981604 (FQ018666) & 6 & -3 & 128 & $\begin{array}{l}\text { gb|AAN63675.1|AF448448_1 chemosensory } \\
\text { protein [Helicoverpa zea] }\end{array}$ & $2 e-48$ & $81 \%$ & YES \\
\hline $\begin{array}{l}\text { EZ983373 (GW825922 EZ982648 } \\
\text { HO118345) }\end{array}$ & 3 & -2 & 120 & $\begin{array}{l}\text { ref|NP_ } 001037180.1 \mid \text { chemosensory protein } \\
\text { CSP2 [Bombyx mori] }\end{array}$ & $4 e-45$ & $64 \%$ & YES \\
\hline EZ982930 & 4 & +1 & 148 & $\begin{array}{l}\text { gb|ABM67686.1|chemosensory protein CSP1 } \\
\text { [Plutella xylostella] }\end{array}$ & $6 e-40$ & $54 \%$ & YES \\
\hline EZ982103 & 11 & -3 & 266 & $\begin{array}{l}\text { ref|NP_001037069.1/Chemosensory protein } 8 \\
\text { [Bombyx mori] }\end{array}$ & $5 e-58$ & $86 \%$ & YES \\
\hline EZ982609 (FQ016892) & 4 & +1 & 127 & $\begin{array}{l}\text { gb|AAV34687.1|chemosensory protein } 2 \\
\text { [Heliothis virescens] }\end{array}$ & $1 e-48$ & $87 \%$ & YES \\
\hline EZ983355 & 3 & +1 & 123 & $\begin{array}{l}\text { ref|NP_001037065.1/Chemosensory protein } 6 \\
\text { [Bombyx mori] }\end{array}$ & $6 e-41$ & $60 \%$ & YES \\
\hline GW825956 & 1 & +1 & 128 & $\begin{array}{l}\text { gb|ABM67689.1|chemosensory protein CSP2 } \\
\text { [Spodoptera exigua] }\end{array}$ & $9 e-59$ & $96 \%$ & YES \\
\hline HO118383 (FQ020895) & 1 & +2 & 122 & $\begin{array}{l}\text { ref|NP_001091779.1|chemosensory protein } 11 \\
\text { [Bombyx mori] }\end{array}$ & $3 e-29$ & $80 \%$ & YES \\
\hline
\end{tabular}


lipophilic molecules. However, alignment with Lepidoptera Takeout or juvenile hormone-binding proteins was not possible. Further molecular (eg localisation of the expressing cells) and functional (eg binding properties) analyses are now needed to definitely annotate this new protein as an OBP.

Although the best BLASTX hit for two unigenes, the contig EZ983259 and the singleton FQ014244, consisted of putative BmorOBPs, they could not be aligned with insect OBPs and both presented similarity with juvenile hormone-binding protein and Takeout-like proteins. Thus, they were not included in the following phylogenetic analyses.

A phylogenetic analysis of OBPs (Figure 4) was carried out using protein sequences from S. littoralis, B. mori and other Lepidoptera (accession numbers provided in additional file 6). In view of these analyses, at least one lepidopteran orthologue could be found for each putative SlitOBP identified, except for the new type of OBP identified in this study (FQ020630). In particular, we were able to annotate three SlitPBPs (EZ982949= SlitPBP1; EZ981038 = SlitPBP2; EZ983456 = SlitPBP3) and two SlitGOBPs (EZ982647 = SlitGOBP1 and EZ981811 = SlitGOBP2). Since we found one candidate in each of the three lepidopteran PBP lineages and in each of the two GOBP lineages, it suggests that we identified the complete repertoire of these OBP families in S. littoralis. Interestingly, the BLASTX best hit for EZ981091 was S. frugiperda PBP4, but the phylogenetic position of the protein translated from this contig strongly argues that it does not belong to the PBP family.

\section{Identification of S. littoralis candidate chemosensory receptors \\ 31 candidate chemosensory receptors were identified in male antennae}

The chemosensory receptor family includes ORs and gustatory receptors (GRs). In B. mori, the recently available sequenced genome offered the opportunity to identify the almost complete repertoires of ORs [20,21] and GRs [47] in a lepidopteran species. 41 candidate B. mori ORs (BmorORs) previously identified [20] were compared to the unigenes using TBLASTN, leading to a first identification of 25 putative ORs in S. littoralis (SlitORs). Only six BmorORs gave no result when used as query sequences (BmorOR17, 18, 21, 22, 23 and 43). In parallel, the Interproscan result was scanned to retrieve sequences including one or more domains related to olfactory reception (IPR004117), resulting in the identification of seven putative ORs. Among them, three new sequences (EZ982994, EZ981047, FQ015038) were not identified during the precedent analysis using BmorORs. Additional searches using described insect OR families
(D. melanogaster, A. gambiae, A. mellifera, T. castaneum, Aedes aegypti), as well as some isolated lepidopteran sequences [22-24,26,27] and additional BmorORs recently identified [21] led to the identification of a total of 35 candidate chemosensory receptor partial sequences: 33 olfactory receptors (SlitORs) and two gustatory receptors (SlitGRs). These $S$. littoralis sequences were in turn employed in searches to find more genes in an iterative process, which did not lead to the identification of additional candidates.

As for OBPs and CSPs, some ORFs appeared to overlap with a high sequence identity, and sequence alignments were further manually analyzed. We propose that the following unigenes encode a single protein: EZ982777/FQ025462 (residual intron in the latter, identified by the presence of intron/exon boundaries), EZ981960/FQ025873/FQ021134 (incomplete 5' end for the singletons and presence of several punctual mutations) and FQ023155/FQ021957. The final number of candidate chemosensory receptors identified is then 31 , including 29 ORs and two GRs, and the corresponding unigenes are listed in table 4.

\section{Putative gustatory receptors expressed in adult antennae}

The two GR candidates are, to our knowledge, the first identified in Lepidoptera antennae. It is not surprising to find candidate GRs since these organs are known to carry some taste sensilla [48]. Interestingly, one of these GRs (GW825869) presented similarity with members of the GR21a family (Table 4). In Drosophila, GR21a forms a heteromeric receptor in combination with GR63a, which allows the detection of $\mathrm{CO}_{2}[49,50]$. Putative $\mathrm{CO}_{2}$ receptors have been described in B. mori [47], one of which (BmGr2NJ as described by [47]) presented $78 \%$ identity with the partial sequence we obtained in $S$. littoralis. Since $\mathrm{CO}_{2}$ receptors are quite conserved among insects [51], this high sequence identity supports the annotation of this $S$. littoralis $\mathrm{GR}$ as a candidate $\mathrm{CO}_{2}$ receptor. Receptor cells to $\mathrm{CO}_{2}$ were found on the antennae of some insect species, such as the honey bee [52] and Drosophila [53], but up to now, moth receptor cells for $\mathrm{CO}_{2}$ have been only described on labial palps [54]. Thus, annotation of this $\mathrm{GR}$ as a candidate $\mathrm{CO}_{2}$ receptor awaits further demonstration of $\mathrm{CO}_{2}$ detection by $S$. littoralis antennae.

\section{Annotation of the S. littoralis putative ORs}

In S. littoralis, 63 glomeruli could be identified in the antennal lobe [55]. Considering the one receptor-one glomerulus paradigm [56,57], by which the number of expected ORs in a given species should correlates with the number of glomeruli in the antennal lobe, we estimate that the 29 candidate OR genes identified represent half of the S. littoralis OR repertoire. $45 \%$ of the SlitOR amino acid sequences showed low sequence conservation with already known receptor proteins (less 


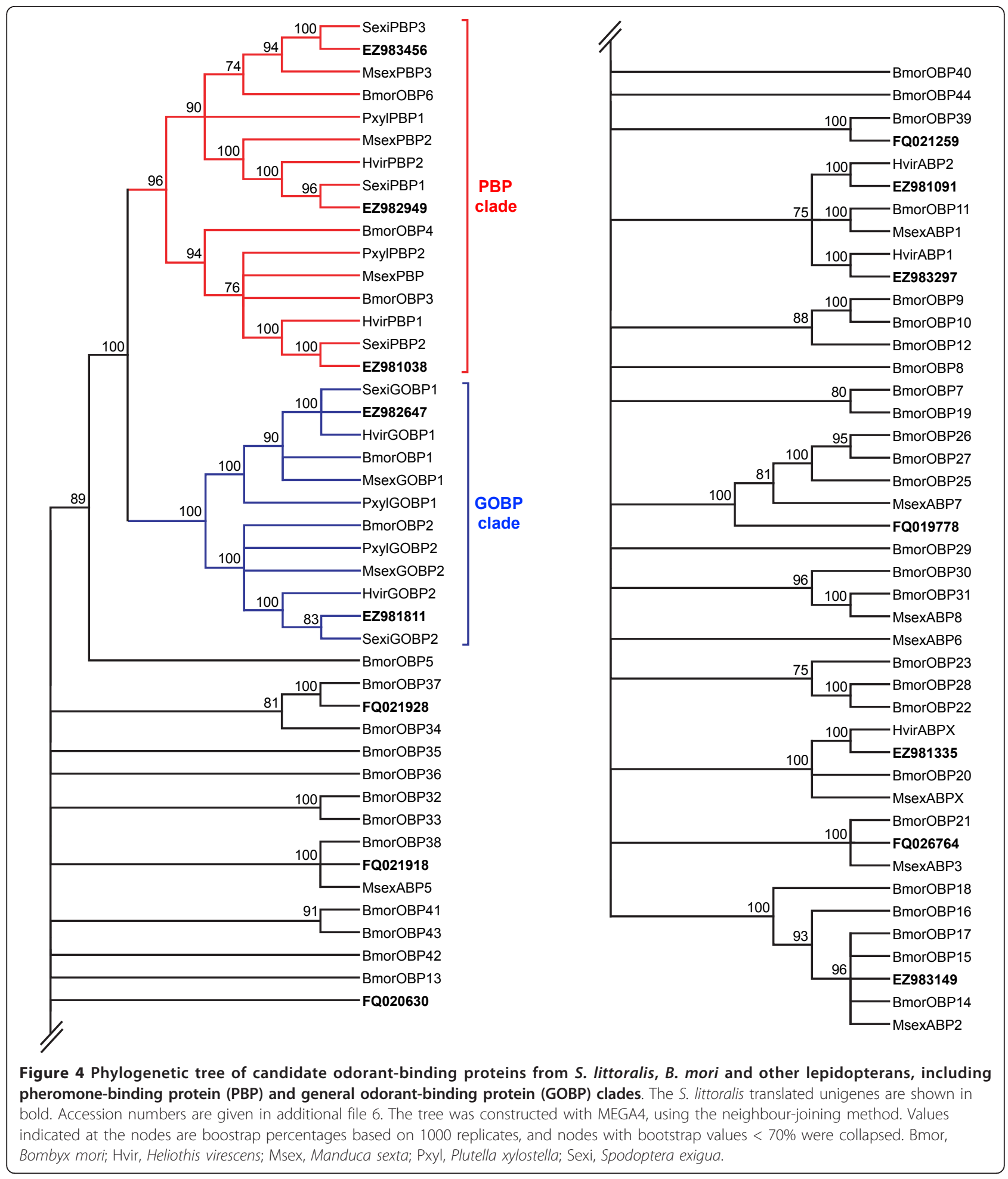

than $50 \%$ identity with the best hit, table 4 ). The remaining SlitORs presented higher conservation (up to $88 \%$ identity with the best hit), and eight SlitORs (26\%) shared more than $70 \%$ identity with their respective best hits (Table 4). Among these conserved sequences, we could recognize SlitOR2 (the D. melanogaster OR83b orthologue, translated from EZ981047) and SlitOR18 (EZ983476), two S. littoralis receptors that we previously identified by homology cloning [25,31]. The predicted translations of four unigenes exhibited a high conservation 
Table 4 List of S. littoralis unigenes putatively involved in chemosensory reception

\begin{tabular}{|c|c|c|c|c|c|c|c|}
\hline $\begin{array}{l}\text { Unigene } \\
\text { reference }\end{array}$ & $\begin{array}{l}\text { EST } \\
\mathrm{nb}\end{array}$ & Frame & $\begin{array}{l}\text { ORF } \\
\text { size } \\
\text { (aa) }\end{array}$ & $\begin{array}{l}\text { Blastx best hit } \\
\text { Reference/Sequence name/species }\end{array}$ & $\begin{array}{l}\mathrm{E} \\
\text { value }\end{array}$ & Identity & $\begin{array}{l}\text { Antennae } \\
\text { enriched }\end{array}$ \\
\hline \multicolumn{8}{|c|}{ Candidate olfactory receptors } \\
\hline EZ982621 & 3 & +1 & 307 & ref|NP_001103623.1|odorant receptor 33 [Bombyx mori] & $2 e-43$ & $31 \%$ & YES \\
\hline EZ981394 & 5 & -2 & 291 & $\begin{array}{l}\text { reff|NP_ } 001091790.1 \mid \text { candidate olfactory receptor } \\
\text { [Bombyx mori] }\end{array}$ & $8 e-98$ & $65 \%$ & YES \\
\hline EZ981024 & 2 & 3 & 335 & dbj|BAH66326.1|olfactory receptor [Bombyx mori] & $1 e-127$ & $70 \%$ & YES \\
\hline EZ981047 & 11 & -1 & 302 & $\begin{array}{l}\text { gb|ABQ82137.1|chemosensory receptor } 2 \text { [Spodoptera } \\
\text { littoralis] }\end{array}$ & $8 e-147$ & $88 \%$ & YES \\
\hline EZ983328 & 7 & +3 & 285 & $\begin{array}{l}\text { emb|CAG38117.1|putative chemosensory receptor } 16 \\
\text { [Heliothis virescens] }\end{array}$ & $1 e-88$ & $57 \%$ & YES \\
\hline $\begin{array}{l}\text { EZ981960 } \\
\text { (FQ025873, } \\
\text { FQ021134) }\end{array}$ & 6 & -2 & 263 & $\begin{array}{l}\text { emb|CAG38117.1|putative chemosensory receptor } 16 \\
\text { [Heliothis virescens] }\end{array}$ & $5 e-99$ & $65 \%$ & YES \\
\hline EZ983448 & 5 & -1 & 329 & $\begin{array}{l}\text { emb|CAD31853.1|putative chemosensory receptor } 7 \\
\text { [Heliothis virescens] }\end{array}$ & $2 e-08$ & $26 \%$ & YES \\
\hline EZ982994 & 5 & 1 & 299 & $\begin{array}{l}\text { ref|NP_001155301.1|olfactory receptor BmOr-60 [Bombyx } \\
\text { mori] }\end{array}$ & $2 e-106$ & $72 \%$ & YES \\
\hline EZ982443 & 4 & -1 & 274 & dbj|BAH66361.1|olfactory receptor [Bombyx mori] & $5 e-13$ & $45 \%$ & N/A \\
\hline EZ981646 & 4 & -3 & 264 & ref|NP_001103476.1|odorant receptor 35 [Bombyx mori] & $1 e-76$ & $55 \%$ & NO \\
\hline $\begin{array}{l}\text { EZ982777 } \\
(\text { FQ025462) }\end{array}$ & 3 & +1 & 299 & $\begin{array}{l}\text { dbj|BAG71423.2|olfactory receptor [Mythimna } \\
\text { separata] }\end{array}$ & $8 e-106$ & $57 \%$ & NO \\
\hline EZ981417 & 3 & +2 & 282 & dbj|BAH66359.1|olfactory receptor [Bombyx mori] & $8 e-30$ & $70 \%$ & YES \\
\hline EZ983476 & 2 & +1 & 331 & $\begin{array}{l}\text { emb|CAG38119.1|putative chemosensory receptor } 18 \\
\text { [Heliothis virescens] }\end{array}$ & $1 e-137$ & $73 \%$ & YES \\
\hline EZ983129 & 2 & -2 & 301 & dbj|BAH66312.1|olfactory receptor [Bombyx mori] & $4 e-69$ & $42 \%$ & YES \\
\hline EZ983645 & 2 & +1 & 165 & $\begin{array}{l}\text { emb|CAG38122.1|putative chemosensory receptor } 21 \\
\text { [Heliothis virescens] }\end{array}$ & $1 e-67$ & $58 \%$ & NO \\
\hline EZ982362 & 2 & -1 & 173 & ref|NP_001104830.1|odorant receptor 41 [Bombyx mori] & 0.95 & $19 \%$ & NO \\
\hline EZ981187 & 2 & +1 & 199 & $\begin{array}{l}\text { gb|ACJ12929.1|odorant receptor } 3 \text { [Epiphyas } \\
\text { postvittana] }\end{array}$ & $1 e-95$ & $63 \%$ & YES \\
\hline EZ982965 & 2 & +2 & 250 & $\begin{array}{l}\text { tpg|DAA05977.1|TPA: TPA_exp: odorant receptor } 19 \\
\text { [Bombyx mori] }\end{array}$ & $1 e-40$ & $39 \%$ & YES \\
\hline GW825563 & & +1 & 250 & dbj|BAH66339.1|olfactory receptor [Bombyx mori] & $2 e-65$ & $82 \%$ & YES \\
\hline $\begin{array}{l}\text { FQ023155 } \\
\text { (FQ021957) }\end{array}$ & & +3 & 189 & $\begin{array}{l}\text { emb|CAG38118.1|putative chemosensory receptor } 17 \\
\text { [Heliothis virescens] }\end{array}$ & $5 e-74$ & $76 \%$ & N/A \\
\hline FQ031836 & & +3 & 239 & ref|NP_001104797.1|odorant receptor 30 [Bombyx mori] & $1 e-41$ & $43 \%$ & YES \\
\hline FQ031000 & & +3 & 223 & $\begin{array}{l}\text { gb|ACS45305.1|candidate odorant receptor } 11 \\
\text { [Helicoverpa armigera] }\end{array}$ & $2 e-109$ & $85 \%$ & YES \\
\hline FQ030158 & & +1 & 254 & $\begin{array}{l}\text { emb|CAD31949.1|putative chemosensory receptor } 8 \\
\text { [Heliothis virescens] }\end{array}$ & $4 e-49$ & $50 \%$ & YES \\
\hline FQ029014 & & +3 & 217 & $\begin{array}{l}\text { gb|ACM18061.1|putative odorant receptor OR3 [Manduca } \\
\text { sexta] }\end{array}$ & $1 e-09$ & $28 \%$ & N/A \\
\hline FQ016760 & & +2 & 266 & $\begin{array}{l}\text { ref|XP_312381.1|candidate odorant receptor } \\
(\text { AGAP0 02558-PA) [Anopheles gambiae str. PEST }\end{array}$ & 23 & $28 \%$ & YES \\
\hline FQ017398 & & +2 & 310 & $\begin{array}{l}\text { reff|NP_ } 001091789.1 \mid \text { candidate olfactory receptor } \\
\text { [Bombyx mori] }\end{array}$ & $2 e-57$ & $49 \%$ & YES \\
\hline FQ018861 & & +2 & 229 & dbj|BAH66348.1|olfactory receptor [Bombyx mori] & $2 e-44$ & $35 \%$ & $\mathrm{~N} / \mathrm{A}$ \\
\hline FQ014255 & & +2 & 258 & ref|NP_001103476.1|odorant receptor 35 [Bombyx mori] & $1 e-73$ & $48 \%$ & YES \\
\hline FQ015038 & & +3 & 285 & $\begin{array}{l}\text { ref|NP_001116817.1|olfactory receptor-like receptor } \\
\text { [Bombyx mori] }\end{array}$ & $1 e-94$ & $60 \%$ & YES \\
\hline \multicolumn{8}{|c|}{ Candidate gustatory receptors } \\
\hline FQ016677 & & +2 & 267 & $\begin{array}{l}\text { ref|XP_001848689.1/gustatory receptor } 24 \text { [Culex } \\
\text { quinquefasciatus] }\end{array}$ & $3 e-41$ & $38 \%$ & NO \\
\hline GW825869 & & +3 & 227 & $\begin{array}{l}\text { ref|XP_001654839.1|Gustatory receptor 21a, putative } \\
\text { [Aedes aegypti] }\end{array}$ & $4 e-73$ & $57 \%$ & N/A \\
\hline
\end{tabular}


level (from 57 to $85 \%$ identity, table 4) with lepidopteran PRs previously described $[21,22,26]$. Since lepidopteran PRs form a relatively well conserved lineages [24], these unigenes could encode candidate PRs in S. littoralis.

A phylogenetic analysis was conducted with the putative SlitORs and other lepidopteran OR sequences, including the annotated BmorORs (accession numbers provided in additional file 6) (Figure 5). At least one lepidopteran orthologue could be assigned to the majority of the putative SlitORs, only five of them having no counterpart. Without surprise, the highly conserved SlitOR2 (EZ981047) clustered with other OR2 sequences (D. melanogaster OR83b orthologues) (Figure 5). In correlation with the BLAST results, the four candidate SlitPRs clustered in the lepidopteran PR clade, supporting their annotation.

\section{qPCR analysis of S. littoralis chemosensory receptors}

Insect chemosensory receptors usually exhibit a specific or enriched expression in chemosensory organs $[13,20,27]$. We thus conducted a preliminary study on a single set of samples and considering a single time point, using quantitative real-time PCR, to address the tissue-distribution of the candidate chemosensory receptors we identified in $S$. littoralis. Data were obtained for 26 unigenes (Figure 6A). For the others, we encountered primer design problems and/or bad efficiencies. As expected, most of our candidates were expressed in a tissue-specific manner, being enriched in chemosensory tissues (antennae and/or proboscis), thus supporting our annotation. EZ983645 was expressed in all tissues tested, unexpected for a chemosensory receptor. One of the two GR candidates expressed in the antennae (FQ016677) appeared to be also well expressed in the proboscis, supporting its annotation. Interestingly, two candidate ORs were well expressed in the proboscis (EZ981646 and EZ982362). Consistent with this observation, a previous study demonstrated that the taste organ of the mosquito $A$. gambiae does express ORs and exhibited olfactory responses [58].

Since pheromone receptors are usually male-specific or male-enriched $[22-24,59,60]$, we next compared SlitOR expression levels between male and female antennae (Figure 6B). Although this preliminary analysis is of limited value, we found that four unigenes were enriched in male antennae (EZ981394, EZ982621, EZ983328 and EZ982777) (Figure 6B). Only two of them (EZ983328 and EZ982777) corresponded to the SlitORs annotated as putative PRs after the BLAST and phylogenetic analyses (see paragraph above). The two additional putative ORs enriched in male antennae (EZ981394 and EZ982621) did not present high sequence identities with other moth PR candidates or functionally characterized PRs.
Other genes putatively involved in the olfactory process and its modulation

lonotropic receptors (IRs), sensory neuron membrane proteins (SNMPs) and transduction

Recently, the ionotropic receptors (IRs), that constitute a family of ionotropic glutamate receptor-related proteins, have been identified as defining a new class of chemosensory receptors in D. melanogaster [61]. The 61 described $D$. melanogaster IRs were used to search for homologues in the $S$. littoralis ESTs by TBLASTN. This led to the identification of five putative S. littoralis IRs. However, further studies are needed to annotate these candidates as IRs or classical glutamate receptors, such as obtaining the full length sequences for detailed examination of the binding site.

We also identified two unigenes encoding putative SNMPs, annotated as SNMP1 and SNMP2 in accordance with their best hit (accession numbers: EZ982816 and EZ982501, additional files 1 and 2). SNMPs were first identified in pheromone-sensitive neurons of Lepidoptera $[10,62]$ and are thought to play a role in pheromone detection, as demonstrated for the D. melanogaster SNMP1 homologue [11].

Our EST analyses (see above) revealed that the antennae appeared to be enriched in genes involved in metabotropic activity. Among examples, we annotated unigenes putatively encoding proteins such as G-proteins and G-protein related elements, second messenger-related enzymes and ions channels such as voltage-gated ion channels, calcium and chloride channels (additional files 1 and 2). Some of these genes have been previously described in detail, such as a diacylglycerol kinase [63] and a transient receptor potential channel [64], whose function in pheromone signal transduction was suspected. However, the way insect ORs transduce the signal is currently under debate and although a classical metabotropic pathway via G-protein was assumed [65], recent studies proposed an alternative or complementary ionotropic process $[66,67]$.

\section{Modulation/regulatory process}

Unigenes were identified as encoding proteins putatively involved in modulation/regulatory process, such as hormone receptors (including ecdysone receptors EcR and USP), juvenile hormone-binding proteins, Takeout-like proteins and biogenic amine receptors (additional files 1 and 2). Consistent with the present data, we have previously characterized an octopamine/tyramine receptor expressed in the olfactory sensilla of an other noctuid, Mamestra brassicae [68]. Biogenic amines act as neurohormones, neuromodulators or neurotransmitters in most invertebrate species [69], and evidence has been accumulated over the last decades that such biogenic amines participate in the modulation of olfactory reception $[70,71]$. Ecdysone and juvenile hormone are key 


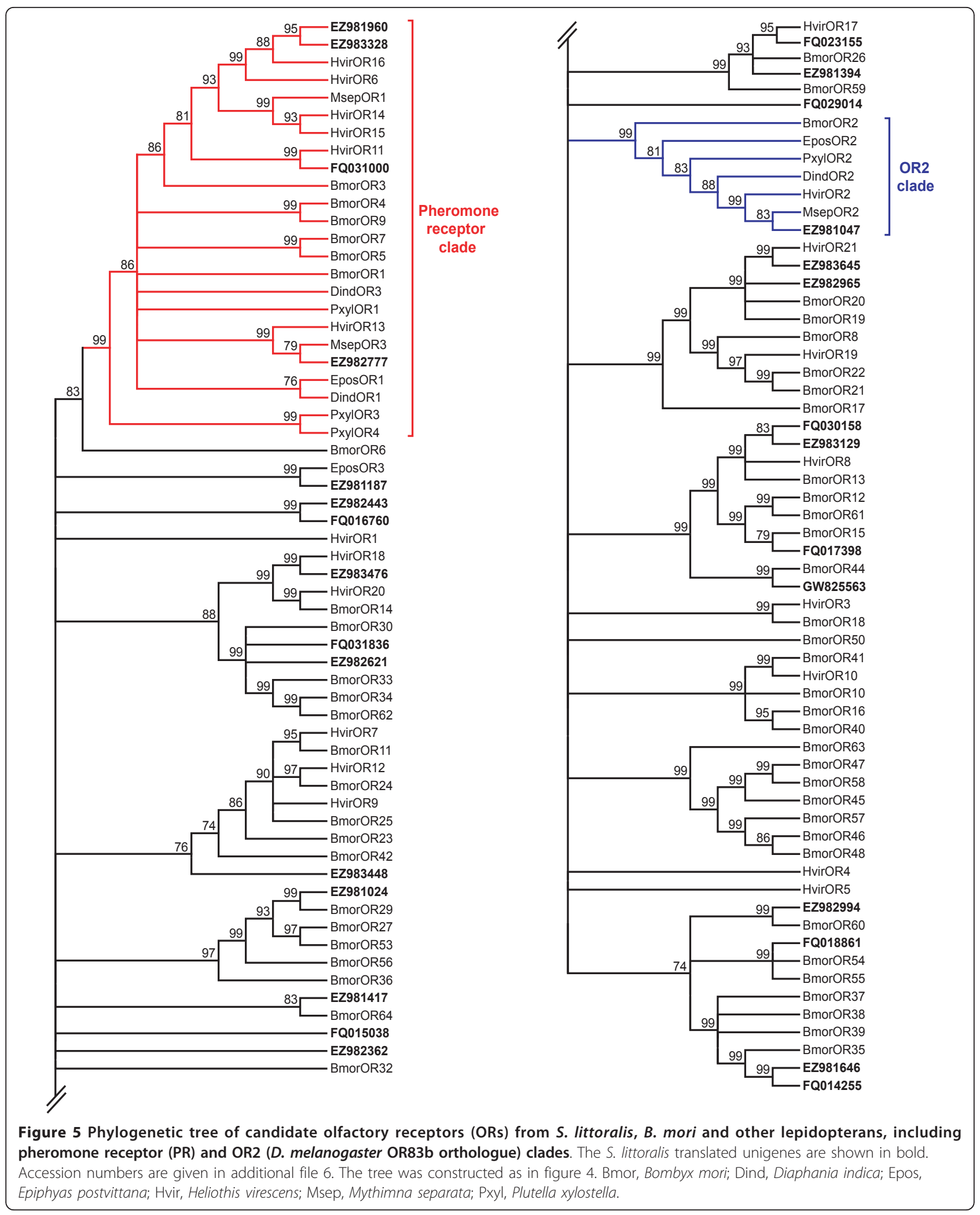




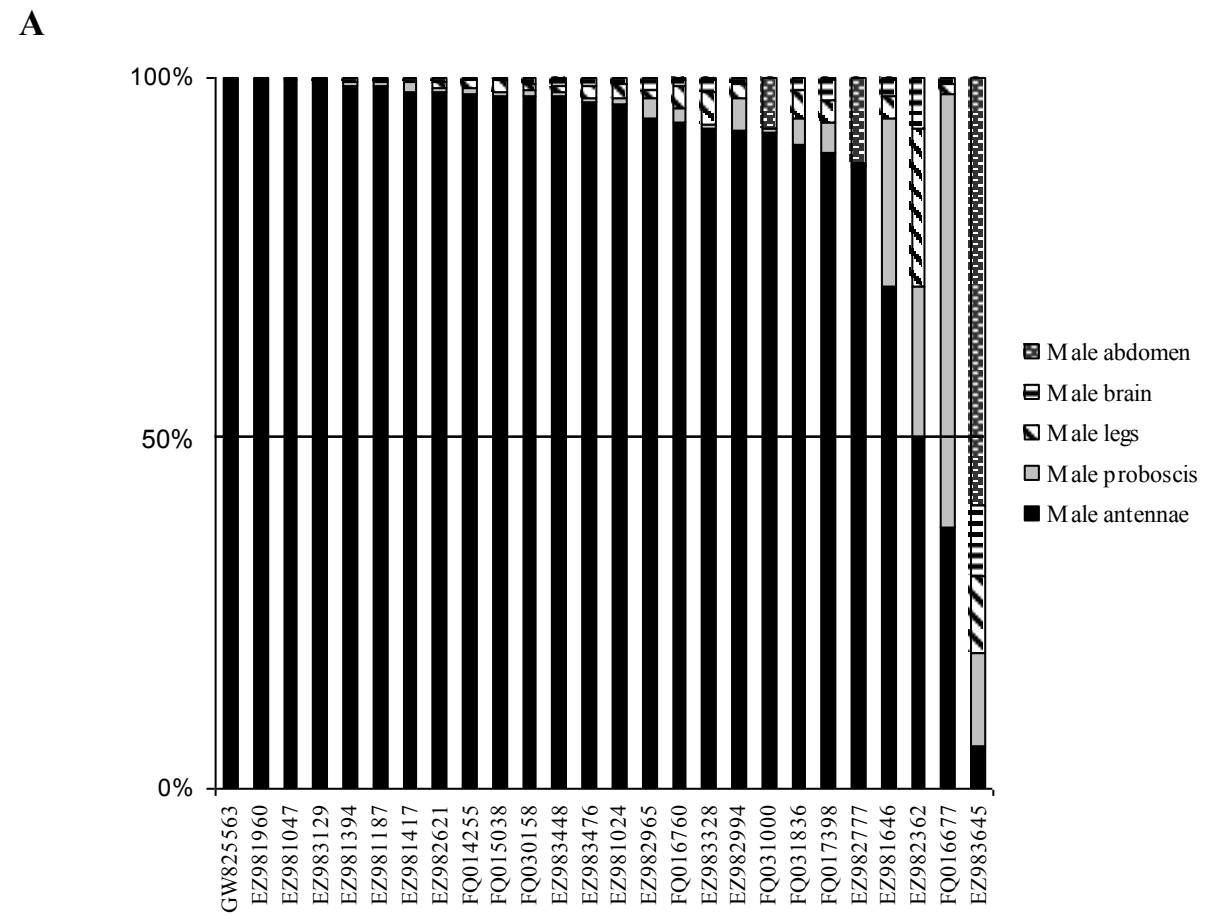

B

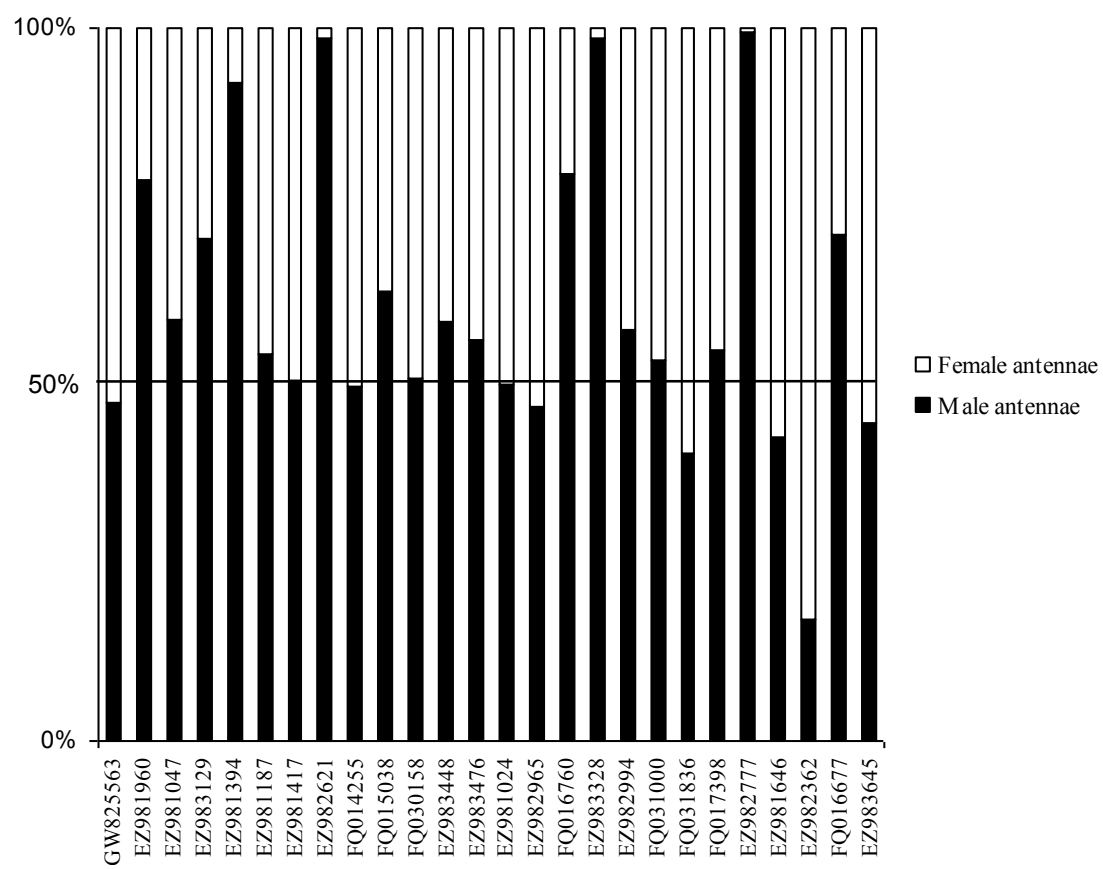

Figure 6 Distribution pattern of S. littoralis candidate olfactory and gustatory receptors in different male tissues (A) and in male and female antennae (B). Gene expression levels were determined by real-time PCR and calculated relatively to the expression of the rpL8 control gene and expressed as the ratio $=E_{S \text { litCR }}{ }^{(\Delta C T ~ S l i t C R)} / E_{r p L 8}(\Delta C T$ rpL8). The $Y$-axis shows the percentage of expression in each tissue with a total of $100 \%$ and the $X$-axis reports the accession numbers of the candidate olfactory and gustatory receptors. See table 4 for unigene details. 
hormones involved in the maturation [72] and the plasticity [73] of the olfactory system.

Among our unigenes, we have also annotated putative circadian clock components. In addition to the previously described period and cryptochrome genes [74], we identified in S. littoralis antennae other fragments homolog to circadian clock encoding genes, such as timeless and vrille (additional files 1 and 2). These data support our previous finding that $S$. littoralis antennae house a peripheral circadian clock [74].

\section{LepidoDB implementation}

Lepido-DB (http://www.inra.fr/lepidodb) is a centralized bioinformatic resource for the genomics of major lepidopteran pests [75]. This Information System was designed to store, organize, display and distribute various genomic data and annotations. Beside a BLAST search and a full text search facilities, the system was constructed using open source software tools from the Generic Model Organism Database (GMOD) including a Chado database. All the data, unigenes, ORFs and their annotation generated in this project have been included in LepidoDB. As a result, from the project page http://www.inra.fr/lepidodb/spodoptera_littoralis one can retrieve the whole sequence set, query with a keyword and retrieve the corresponding sequences.

\section{Conclusions}

The main objective of this study was to identify genes potentially involved in olfactory signal detection in a crop pest model, S. littoralis. We annotated a total of $\sim 130$ unigenes encoding putative proteins involved in all the steps of ligand detection (transport, docking, recognition, degradation). In particular, the normalization process, alongside with the high number of sequenced ESTs compared to previous antennal libraries, allowed enriching the EST collection in rare or low abundant transcripts. This strategy appeared to be particularly relevant for the identification of new insect chemosensory receptors in a species for which no genomic data are available. Concerning the pheromone detection process, we identified in this species three PBPs, two SNMPs, candidates PRs and many CXEs as putative PDEs, as a prerequisite to further identify which $\mathrm{PBP} /$ $\mathrm{PR} / \mathrm{SNMP} / \mathrm{PDE}$ act in concert to ensure the specificity of the recognition process within a given functional type of pheromone-sensitive sensilla. Their respective expression patterns remain to be elucidated to crack the code of their combinatorial expression.

Our analyses also suggest that the olfactory sensitivity may be modulated as early as the antennal level, before signal integration in the brain. Indeed, we annotated a long list of biogenic amine/hormone targets and circadian elements expressed in the antennae, as a first step toward understanding olfactory plasticity at the peripheral level.

Moreover, our study revealed that antennae express abundant defense-related elements involved in xenobiotic and pathogen protection. This observation could be explained by the fact that antennae, whose morphology is adapted to let odorant molecules enter the organism, represent an open space for harmful molecules.

Besides olfaction, insect antennae are involved in different non-olfactory processes, such as taste, balance/ gravity, wind and sound sensing [76-78], and, as recently demonstrated, sun compass orientation [79]. The availability of an antennal transcriptome is thus a valuable resource for olfaction and pheromone detection studies, but also for investigation of the molecular bases of other antennal functions.

\section{Methods}

Insect rearing and male antennae cDNA library construction

Insects originated from our inbred laboratory strain of S. littoralis. Insects were reared on semi-artificial diet [80], under $23^{\circ} \mathrm{C}, 60-70 \%$ relative humidity and $16: 8$ light:dark cycle. Pupae were sexed and males and females were kept separately. Antennae were collected from 1-2 day old naïve adult males and stored at $-80^{\circ} \mathrm{C}$ until we obtained a total number of 12000 antennae. Two mg of total RNA were isolated using the TriZol reagent (Invitrogen, Carlsbad, CA, USA), quantified in a spectrophotometer, and the quality verified by agarose gel electrophoresis. A custom normalized EvoQuest ${ }^{\mathrm{TM}} \mathrm{cDNA}$ library was created by Invitrogen in the pSPORT 6.1 vector, using $1 \mathrm{mg}$ of total RNA as starting material, without any amplification. The normalization step (performed by Invitrogen) introduced in the library construction consisted of a single stranded antisense DNA target-biotinylated sense RNA driver hybridization and a capture with streptavidin to remove target/driver hybrids and un-hybridized drivers, leftover DNA representing the normalized library. This led to a 20 fold reduction of abundant genes as measured for $\beta$-actin, while maintaining a good average insert size of $2.1 \mathrm{~kb}$. The normalization procedure was used to minimize EST redundancy and to enrich the library for rare and low abundant genes, to allow new gene discovery.

\section{EST sequencing}

The library was plated, and 2400 clones were randomly picked. Their 5' ends were sequenced using REV primer (Genome-express, Grenoble, France). 93\% of the clones (2218) presented an insert, we thus undertook a highthroughput sequencing project (20000 sequences) in partnership with the Genoscope (Evry, France). The 
plated library was arrayed robotically and bacterial clones had their plasmid DNA amplified using phi29 polymerase. The plasmids were end-sequenced using BigDye Termination kits on Applied Biosystems 3730xl DNA Analysers. Adaptor and vector were localized using cross_match (http://www.phrap.org/) using default matrix ( 1 for a match, -2 penalty for a mismatch), with mean scores of 6 and 10, respectively. Sequences were then trimmed following three criteria: vector and adaptor, poly(A) tail or low quality (defined as at least 15 among 20 bp with a phred score below 12). Moreover, while submitting the unigenes to GenBank, the sequences were also compared to known vectors using the vecscreen software (http://www.ncbi.nlm.nih.gov/ VecScreen/VecScreen.html). We finally obtained the 5' end sequences of 20760 ESTs.

\section{Sequence processing, assembly, unigene and peptide generation}

EST assembly was processed using the TGI Clustering tools (TGICL, http://compbio.dfci.harvard.edu/tgi/software) using the default parameters (minimum percent identity for overlaps: 94 , minimum overlap length: 30 bp, maximum length of unmatched overhangs: 30), generating unigenes and singletons. Peptides were extracted from the unigenes using FrameDP 1.03 [81], with three training iterations and using Swissprot (398 181 entries, August 2009) as reference protein database.

\section{Specificity analysis using EST}

The unigenes were compared to the 550623 lepidopteran ESTs retrieved from the NCBI Entrez server (July 2009), using BLASTN with an e-value cut-off of 1e-10. The analysis of the enrichment of the EST library was performed with the help of the BLAST2GO application [82] using GOSSIP [83]. In this application, GO terms are tested for enrichment in a test group when compared to a reference group using Fisher's exact test with multiple testing correction. The statistical tests were achieved with the $\mathrm{R} \mathrm{t}$-test and Chi2 methods.

\section{Gene identification and functional annotation}

The unigenes were compared to the NCBI non redondant protein database (7686184 entries, July 2009 version), the FlyBase translational database v5.16 [84] (21 647 entries) and 14623 B. mori Glean peptide predictions from SilkDB (April 2008 release, ftp://silkdb.org/ pub/current/Gene/Glean_genes/silkworm_glean_pep.fa. tar.gz) [85] using BLASTX, with a 1e-5 e-value threshold. The Gene Ontology mapping and distribution were done with the help of BLAST2GO (GO association done by a BLAST against the NCBI NR database). Finally, the functional domain protein profile and domain were predicted by queries against InterPro using InterproScan [37], running a batch of analyses (BLASTProDom, Coil, FprintScan, Gene3D, HMMPanther, HMMPfam, HMMPIR, HMMSmart, HMMTigr, PatternScan, ProfileScan, RNA-BINDING, Seg and Superfamily) on the predicted ORFs. The protein sequences were searched for the occurrence of a signal peptide using SignalP 3.0 [44].

\section{Identification of odorant-binding proteins and chemosensory receptors}

The $S$. littoralis antennal unigenes were searched with B. mori OBPs, CSPs, chemosensory receptors and all available insect ORs retrieved from Swissprot as queries using TBLASTN [86]. Additionally, the Interproscan results were scanned for the Interpro accession IPR006170 (Pheromone/general odorant-binding protein, $\mathrm{PBP} / \mathrm{GOBP}$ Molecular Function: odorant binding GO:0005549) and IPR004117 (Molecular Function: olfactory receptor activity GO:0004984). S. littoralis putative chemosensory receptor sequences were in turn employed in searches to find more genes in an iterative process.

\section{Phylogenetic analyses}

We built OBP and OR neighbor-joining trees based on Lepidoptera data sets. The OBP data set contained the 43 complete amino acid sequences deduced from the genome of B. mori, together with the largest OBP repertoires characterized within noctuid moths (7 sequences from $H$. virescens and 5 from Spodoptera exigua) and outside noctuid moths (13 from M. sexta and 4 from Plutella xylostella) (Accession numbers available in additional file 6). Signal peptide sequences were removed following predictions of cleavage site location made by SignalP 3.0. The OR data set contained 58 amino acid sequences from $B$. mori (6 sequences were removed from the alignment because of their short length) and the 21 sequences characterized from $H$. virescens, completed with subsets of sequences characterized within noctuids (3 sequences from Mythimna separata) and outside noctuids (4 from P. xylostella, 3 from Diaphania indica and 3 from $E$. postvittana). Amino acid sequences were aligned using ClustalW2 [87]. Unrooted trees were constructed by the neighbour-joining method, with Poisson correction of distances, as implemented in MEGA4 software [88]. Node support was assessed using a bootstrap procedure base on 1000 replicates, and nodes supported by a bootstrap value under $70 \%$ were collapsed to an horizontal line when drawing cladograms.

\section{Quantitative real-time PCR}

Naïve males and females in the middle of their second scotophase were used in the following experiments. Male 
antennae, proboscis, legs (mixture of front, middle, and hind legs), brains, abdomens and female antennae were collected and stored at $-80^{\circ} \mathrm{C}$. Total RNAs were extracted with the RNeasy ${ }^{\circledR}$ MicroKit (Qiagen, Hilden, Germany) that included a DNase treatment. Single-stranded cDNAs were synthesized from $1 \mu \mathrm{g}$ of total RNAs with $200 \mathrm{U}$ of M-MLV reverse transcriptase (Clontech, Mountain View, CA, USA) using buffer and protocol supplied in the Advantage ${ }^{\circledR}$ RT-for-PCR kit (Clontech). Gene-specific primers for $S$. littoralis chemosensory receptors and the endogenous control rpL8 were designed using the Beacon Designer 4.0 software (Bio-Rad, Hercules, CA, USA), yielding PCR products ranging from 100 to $250 \mathrm{bp}$ (see additional file 7). qPCR mix was prepared in a total volume of $20 \mu \mathrm{l}$ with $10 \mu \mathrm{l}$ of Absolute QPCR SYBR Green Mix (ThermoFisher Scientific, Epsom, UK), $5 \mu \mathrm{l}$ of diluted cDNA (or water for the negative control or RNA for controlling for the absence of genomic DNA) and $200 \mathrm{nM}$ of each primer. qPCRs were performed on S. littoralis cDNAs using a MJ Opticon Monitor Detection System (Bio-Rad). The PCR program began with a cycle at $95^{\circ} \mathrm{C}$ for $15 \mathrm{~min}$, followed by 40 cycles of $20 \mathrm{~s}$ at $95^{\circ} \mathrm{C}, 15 \mathrm{~s}$ at 53 to $62^{\circ} \mathrm{C}$ (depending on the primer pair) and $20 \mathrm{~s}$ at $72^{\circ} \mathrm{C}$. To assess the purity of the PCR reactions, a dissociation curve of the amplified product was performed by gradual heating from $50^{\circ} \mathrm{C}$ to $95^{\circ} \mathrm{C}$ at $0.2^{\circ} \mathrm{C} / \mathrm{s}$. Standard curves were generated by a five-fold dilution series of a cDNA pool evaluating primer efficiency $\mathrm{E}\left(\mathrm{E}=10^{(-1 / \text { slope })}\right)$. All reactions were performed in duplicate. Chemosensory receptor expression levels were calculated relatively to the expression of the rpL8 control gene and expressed as the ratio $=\mathrm{E}_{\mathrm{SlitCR}}{ }^{(\Delta \mathrm{CT} \text { SlitCR })} / \mathrm{E}_{\mathrm{rpL} \text { 8 }}{ }^{(\Delta \mathrm{CT} \text { rpL8)}}[89]$.

\section{Additional material}

Additional file 1: Full description of S. littoralis ESTs, including accession number, sequence, length, accession number of the corresponding contig if any and blast hit.

Additional file 2: Full description of $S$. littoralis unigenes, including accession number, gene size, ORF length, EST coverage, blast, signalP analysis, unigene sequence, ORF sequence.

Additional file 3: Table of the GO terms over or under represented in S. littoralis ORFs having no similarity with the $B$. mori proteome. Test group: ORFs with no match. Reference group: ORFs with at least one match. Fisher's exact test with multiple testing correction.

Additional file 4: Table of the Interproscan results for the 678 $S$. littoralis unigene sequences having no similarity with any known proteins.

Additional file 5: Table of the GO terms over or under represented in S. littoralis unigenes having no lepidopteran EST match. Test group: S. littoralis ESTs with no match. Reference group: S. littoralis ESTS with at least one match. Fisher's exact test with multiple testing correction.

Additional file 6: Accession numbers for amino acid sequences of the lepidopteran odorant-binding proteins, antennal binding proteins, chemosensory proteins and olfactory receptors used in the phylogenetic analyses.
Additional file 7: Table reporting the forward and reverse primer sequences used in real-time PCR, annealing temperatures, resulting amplicon lengths and PCR efficiencies.

\section{List of abbreviations}

ABP: antennal-binding protein; CSP: chemosensory protein;

CXE: carboxylesterase; EST: expressed sequenced tag; GOBP: general odorantbinding protein; GR: gustatory receptor; OBP: odorant-binding protein; ODE: odorant-degrading enzyme; OR: olfactory receptor; ORF: open reading frame; PBP: pheromone-binding protein; PDE: pheromone-degrading enzyme; PR: pheromone receptor; SNMP: sensory neuron membrane protein.

\section{Acknowledgements}

We thank Fabien Tissier and Pascal Roskam for insect rearing, David Tepfer for english improvement, the BioGenouest platform, especially Anthony Bretaudeau, Aurélien Roult and Olivier Collin for their bioinformatics support, and we thank reviewers for in depth comments on the manuscript. This work was supported by INRA AIP "Séquençage-génotypage", Université Pierre et Marie Curie (UPMC), ANR-07-NEURO-037-01 and ANR-09-BLAN0239-01 funding.

\section{Author details}

${ }^{1}$ IRISA, équipe Symbiose, Campus universitaire de Beaulieu, 35042 Rennes Cedex, France. ' INRA, UMR-A 1272 INRA-UPMC PISC Physiologie de I'Insecte: Signalisation et Communication, route de Saint-Cyr, 78026 Versailles Cedex, France. ${ }^{3}$ INRA, UMR 1231 INRA-Université Montpellier II BIVI, Place Eugène Bataillon, 34095 Montpellier Cedex 5, France. ${ }^{4}$ Genoscope, Centre National de Séquençage, 2 rue Gaston Crémieux, BP 191, F-91057 Evry Cedex, France. ${ }^{5}$ UMR 5548, University of Bourgogne, 6 bd Gabriel, F-21000 Dijon, France. ${ }^{6}$ Department of Neurobiology, University of Massachusetts Medical School, 01604, Worcester, MA, USA.

\section{Authors' contributions}

FL, SM and FC carried out the bioinformatic analyses. NM performed the sequence alignments and the phylogenetic analyses. ChMe and MCF collected the antennae and prepared the RNA, and ChMe participated in drafting the manuscript. MMC participated in olfactory gene annotation and in drafting the manuscript. FG and JP coordinated and performed the EST sequencing at Genoscope Evry. ChMo designed and performed the qPCR analyses. EJJ conceived and coordinated the study, participated in olfactory gene annotation and in drafting the manuscript. All authors read and approved the final manuscript.

Received: 16 April 2010 Accepted: 29 January 2011 Published: 29 January 2011

\section{References}

1. Roelofs WL: Chemistry of sex attraction. Proc Natl Acad Sci USA 1995, 92:44-49.

2. Kaissling KE: Physiology of pheromone reception in insects (an example of moths). ANIR 2004, 6:73-91.

3. Touhara K, Vosshall LB: Sensing odorants and pheromones with chemosensory receptors. Annu Rev Physiol 2009, 71:307-332.

4. Witzgall $P$, Kirsch $P$, Cork $A$ : Sex pheromones and their impact on pest management. J Chem Ecol 36:80-100.

5. Rutzler $M$, Zwiebel $L$ : Molecular biology of insect olfaction:recent progress and conceptual models. J Comp Physiol A Neuroethol Sens Neural Behav Physiol 2005, 191:777-790.

6. Vogt RG, Lerner MR: Two groups of odorant binding proteins in insects suggest specific and general olfactory pathways. Neurosci Abst 1989, 15:1290.

7. Vogt RG: Biochemical diversity of odor detection:OBPs, ODEs and SNMPs. In Insect Pheromone Biochemistry and Molecular Biology. Edited by: Blomquist GJ, Vogt RG. Elsevier Academic Press; 2003:391-445.

8. Pelosi P, Zhou JJ, Ban LP, Calvello M: Soluble proteins in insect chemical communication. Cell Mol Life Sci 2006, 63:1658-1676.

9. Jacquin-Joly E, Merlin C: Insect olfactory receptors: contributions of molecular biology to chemical ecology. J Chem Ecol 2004, 30:2359-2397. 
10. Rogers ME, Krieger J, Vogt RG: Antennal SNMPs (sensory neuron membrane proteins) of Lepidoptera define a unique family of invertebrate CD36-like proteins. J Neurobiol 2001, 49:47-61.

11. Benton R, Vannice KS, Vosshall LB: An essential role for a CD36-related receptor in pheromone detection in Drosophila. Nature 2007, 450:289-293.

12. Pelosi $P$, Maida R: Odorant-binding proteins in insects. Comp Biochem Physiol B Biochem Mol Biol 1995, 111:503-514.

13. Vosshall LB, Amrein H, Morozov PS, Rzhetsky A, Axel R: A spatial map of olfactory receptor expression in the Drosophila antenna. Cell 1999, 96:725-736

14. Clyne PJ, Warr CG, Freeman MR, Lessing D, Kim J, Carlson JR: A novel family of divergent seven-transmembrane proteins: candidate odorant receptors in Drosophila. Neuron 1999, 22:327-338.

15. Gao Q, Chess A: Identification of candidate Drosophila olfactory receptors from genomic DNA sequence. Genomics 1999, 60:31-39.

16. Fox AN, Pitts RJ, Robertson HM, Carlson JR, Zwiebel LJ: Candidate odorant receptors from the malaria vector mosquito Anopheles gambiae and evidence of down-regulation in response to blood feeding. Proc Natl Acad Sci USA 2001, 98:14693-14697.

17. Robertson HM, Wanner KW: The chemoreceptor superfamily in the honey bee, Apis mellifera: expansion of the odorant, but not gustatory, receptor family. Genome Res 2006, 16:1395-1403.

18. Robertson HM, Gadau J, Wanner KW: The insect chemoreceptor superfamily of the parasitoid jewel wasp Nasonia vitripennis. Insect Mol Biol 19(Suppl 1):121-136.

19. Abdel-Latief M: A Family of Chemoreceptors in Tribolium castaneum (Tenebrionidae: Coleoptera). PLOS ONE 2007, 2:e1319.

20. Wanner KW, Anderson AR, Trowell SC, Theilmann DA, Robertson HM, Newcomb RD: Female-biased expression of odourant receptor genes in the adult antennae of the silkworm, Bombyx mori. Insect Mol Biol 2007, 16:107-119.

21. Tanaka K, Uda Y, Ono Y, Nakagawa T, Suwa M, Yamaoka R, Touhara K: Highly selective tuning of a silkworm olfactory receptor to a key mulberry leaf volatile. Curr Biol 2009, 19:881-890.

22. Mitsuno $H$, Sakurai $T$, Murai M, Yasuda $T$, Kugimiya S, Ozawa R, Toyohara $H_{\text {, }}$ Takabayashi J, Miyoshi H, Nishioka T: Identification of receptors of main sex-pheromone components of three Lepidopteran species. Eur J Neurosci 2008, 28:893-902.

23. Miura N, Nakagawa T, Tatsuki S, Touhara K, Ishikawa $Y$ : A male-specific odorant receptor conserved through the evolution of sex pheromones in Ostrinia moth species. Int J Biol Sci 2009, 5:319-330.

24. Patch HM, Velarde RA, Walden KK, Robertson HM: A candidate pheromone receptor and two odorant receptors of the hawkmoth Manduca sexta. Chem Senses 2009, 34:305-316.

25. Brigaud I, Montagne N, Monsempes C, Francois MC, Jacquin-Joly E: Identification of an atypical insect olfactory receptor subtype highly conserved within noctuids. FEBS J 2009, 276:6537-6547.

26. Krieger J, Grosse-Wilde E, Gohl T, Dewer YM, Raming K, Breer H: Genes encoding candidate pheromone receptors in a moth (Heliothis virescens). Proc Natl Acad Sci USA 2004, 101:11845-11850.

27. Krieger J, Raming K, Dewer YM, Bette S, Conzelmann S, Breer H: A divergent gene family encoding candidate olfactory receptors of the moth Heliothis virescens. Eur J Neurosci 2002, 16:619-628.

28. Larsson MC, Domingos Al, Jones WD, Chiappe ME, Amrein H, Vosshall LB: Or83b encodes a broadly expressed odorant receptor essential for Drosophila olfaction. Neuron 2004, 43:703-714.

29. Benton R, Sachse S, Michnick SW, Vosshall LB: Atypical membrane topology and heteromeric function of Drosophila odorant receptors in vivo. PLoS Biol 2006, 4:e20.

30. Krieger J, Klink O, Mohl C, Raming K, Breer H: A candidate olfactory receptor subtype highly conserved across different insect orders. J Comp Physiol A 2003, 189:519-526.

31. Malpel S, Merlin C, Francois MC, Jacquin-Joly E: Molecular identification and characterization of two new Lepidoptera chemoreceptors belonging to the Drosophila melanogaster OR83b family. Insect Mol Biol 2008, 17:587-596.

32. ISGC: The genome of a lepidopteran model insect, the silkworm Bombyx mori. Insect Biochem Mol Biol 2008, 38:1036-1045.

33. Robertson HM, Martos R, Sears CR, Todres EZ, Walden KK, Nardi JB: Diversity of odourant binding proteins revealed by an expressed sequence tag project on male Manduca sexta moth antennae. Insect Mol Biol 1999, 8:501-518.

34. Jordan MD, Stanley D, Marshall SD, De Silva D, Crowhurst RN, Gleave AP Greenwood DR, Newcomb RD: Expressed sequence tags and proteomics of antennae from the tortricid moth, Epiphyas postvittana. Insect $\mathrm{Mol}$ Biol 2008, 17:361-373.

35. Ljungberg $\mathrm{H}$, Anderson $\mathrm{P}$, Hansson BS: Physiology and morphology of pheromone-specific sensilla on the antennae of male and female Spodoptera littoralis (Lepidoptera: Noctuidae). J Insect Physiol 1993, 39:253-260.

36. Vogel H, Heidel AJ, Heckel DG, Groot AT: Transcriptome analysis of the sex pheromone gland of the noctuid moth Heliothis virescens. BMC Genomics 11:29.

37. Quevillon E, Silventoinen V, Pillai S, Harte N, Mulder N, Apweiler R, Lopez R: InterProScan: protein domains identifier. Nucleic Acids Res 2005, 33 : W116-120.

38. Vogt RG, (Ed.): Molecular basis of pheromone detection in insects.Edited by: Elsevier. London: Elsevier; 2005.

39. Ferkovich SM, Van Essen F, Taylor TR: Hydrolysis of sex pheromone by antennal esterases of the cabbage looper, Trichoplusia ni. Chem Senses 1980, 5:33-45.

40. Vogt RG, Riddiford LM: Pheromone binding and inactivation by moth antennae. Nature 1981, 293:161-163.

41. Prestwich GD, McGraham SG, Handley M, Latli B, Streinz L, Tasayco MLJ: Enzymatic processing of pheromones and pheromone analogs. Experientia 1989, 45:263-270.

42. Vogt RG, Riddiford LM, Prestwich GD: Kinetic properties of a pheromone degrading enzyme: the sensillar esterase of Antheraea polyphemus. Proc Natl Acad Sci USA 1985, 82:8827-8831

43. Durand N, Carot-Sans G, Chertemps T, Montagne N, Jacquin-Joly E, Debernard S, Maibeche-Coisne M: A diversity of putative carboxylesterases are expressed in the antennae of the noctuid moth Spodoptera littoralis. Insect Mol Biol 2009.

44. Bendtsen JD, Nielsen H, von Heijne G, Brunak S: Improved prediction of signal peptides: SignalP 3.0. J Mol Biol 2004, 340:783-795.

45. Gong DP, Zhang HJ, Zhao P, Xia QY, Xiang ZH: The Odorant Binding Protein gene family from the genome of silkworm, Bombyx mori. BMC Genomics 2009, 10.

46. Gong DP, Zhang HJ, Zhao P, Lin Y, Xia QY, Xiang ZH: Identification and expression pattern of the chemosensory protein gene family in the silkworm, Bombyx mori. Insect Biochem Mol Biol 2007, 37:266-277.

47. Wanner KW, Robertson HM: The gustatory receptor family in the silkworm moth Bombyx mori is characterized by a large expansion of a single lineage of putative bitter receptors. Insect Mol Biol 2008, 17:621-629.

48. Jorgensen K, Almaas TJ, Marion-Poll F, Mustaparta H: Electrophysiological characterization of responses from gustatory receptor neurons of sensilla chaetica in the moth Heliothis virescens. Chem Senses 2007, 32:863-879.

49. Jones WD, Cayirlioglu P, Kadow IG, Vosshall LB: Two chemosensory receptors together mediate carbon dioxide detection in Drosophila. Nature 2007, 445:86-90.

50. Kwon JY, Dahanukar A, Weiss LA, Carlson JR: The molecular basis of CO2 reception in Drosophila. Proc Natl Acad Sci USA 2007, 104:3574-3578.

51. Robertson HM, Kent LB: Evolution of the gene lineage encoding the carbon dioxide receptor in insects. J Insect Sci 2009, 9:19.

52. Winston ML: The biology of the honey bee Harvard University Press; 1991.

53. de Bruyne M, Foster K, Carlson JR: Odor coding in the Drosophila antenna. Neuron 2001, 30:537-552.

54. Bogner F, Boppre M, Ernst KD, Boeckh J: CO2 sensitive receptors on labial palps of Rhodogastria moths (Lepidoptera: Arctiidae): physiology, fine structure and central projection. J Comp Physiol A 1986, 158:741-749.

55. Couton L, Minoli S, Kieu K, Anton S, Rospars JP: Constancy and variability of identified glomeruli in antennal lobes: computational approach in Spodoptera littoralis. Cell Tissue Res 2009, 337:491-511.

56. Couto A, Alenius M, Dickson BJ: Molecular, anatomical, and functional organization of the Drosophila olfactory system. Curr Biol 2005, 15:1535-1547.

57. Fishilevich E, Vosshall LB: Genetic and functional subdivision of the Drosophila antennal lobe. Curr Biol 2005, 15:1548-1553. 
58. Kwon HW, Lu T, Rutzler M, Zwiebel LJ: Olfactory responses in a gustatory organ of the malaria vector mosquito Anopheles gambiae. Proc Natl Acad Sci USA 2006, 103:13526-13531.

59. Krieger J, Grosse-Wilde E, Gohl T, Breer H: Candidate pheromone receptors of the silkmoth Bombyx mori. Eur J Neurosci 2005, 21:2167-2176.

60. Nakagawa T, Sakurai T, Nishioka T, Touhara K: Insect sex-pheromone signals mediated by specific combinations of olfactory receptors. Science 2005, 307:1638-1642.

61. Benton R, Vannice KS, Gomez-Diaz C, Vosshall LB: Variant ionotropic glutamate receptors as chemosensory receptors in Drosophila. Cell 2009, 136:149-162.

62. Rogers ME, Sun M, Lerner MR, Vogt RG: Snmp-1, a novel membrane protein of olfactory neurons of the silk moth Antheraea polyphemus with homology to the CD36 family of membrane proteins. J biol Chem 1997, 272:14792-14799.

63. Chouquet B, Bozzolan F, Solvar M, Duportets L, Jacquin-Joly E, Lucas $P$, Debernard S: Molecular cloning and expression patterns of a putative olfactory diacylglycerol kinase from the noctuid moth Spodoptera littoralis. Insect Mol Biol 2008, 17:485-493.

64. Chouquet B, Debernard S, Bozzolan F, Solvar M, Maibeche-Coisne M, Lucas P: A TRP channel is expressed in Spodoptera littoralis antennae and is potentially involved in insect olfactory transduction. Insect Mol Biol 2009, 18:213-222.

65. Krieger J, Breer H: Transduction mechanisms of olfactory sensory neurons. In Insect Pheromone Biochemistry and Molecular Biology. Edited by: Blomquist GJ, Vogt RG. Elsevier Academic Press; 2003:593-607.

66. Sato K, Pellegrino M, Nakagawa T, Vosshall LB, Touhara K: Insect olfactory receptors are heteromeric ligand-gated ion channels. Nature 2008, 452:1002-1006.

67. Wicher D, Schafer R, Bauernfeind R, Stensmyr MC, Heller R, Heinemann SH, Hansson BS: Drosophila odorant receptors are both ligand-gated and cyclic-nucleotide-activated cation channels. Nature 2008, 452:1007-1011.

68. Brigaud I, Grosmaitre X, Francois MC, Jacquin-Joly E: Cloning and expression pattern of a putative octopamine/tyramine receptor in antennae of the noctuid moth Mamestra brassicae. Cell Tissue Res 2009, 335:455-463.

69. Evans P: Octopamine. In Comprehensive Insect Physiology, Biochemistry and Pharmacology. Edited by: Kerkurt GA, Gilbert L. Oxford: Pergamon Press; 1985:499-530.

70. Grosmaître X, Marion-Poll F, Renou M: Biogenic amines modulate olfactory receptor neurons firing activity in Mamestra brassicae. Chem Senses 2001, 26:653-661.

71. Pophof B: Octopamine modulates the sensitivity of silkmoth pheromone receptor neurons. J comp Physiol A 2000, 186:307-313.

72. Vogt RG, Rybczynski R, Cruz M, Lerner MR: Ecdysteroid regulation of olfactory protein expression in the developing antenna of the tobacco hawk moth, Manduca sexta. J Neurobiol 1993, 24:581-597.

73. Anton S, Gadenne C: Effect of juvenile hormone on the central nervous processing of sex pheromone in an insect. Proc Natl Acad Sci USA 1999, 96:5764-5767.

74. Merlin C, Lucas P, Rochat D, Francois MC, Maibeche-Coisne M, JacquinJoly E: An antennal circadian clock and circadian rhythms in peripheral pheromone reception in the moth Spodoptera littoralis. J Biol Rhythms 2007, 22:502-514.

75. d'Alençon E, Sezutsu H, Legeai F, Permal E, Bernard-Samain S, Gimenez S, Gagneur C, Cousserans F, Shimomura M, Brun-Barale A, et al: Extensive synteny conservation of holocentric chromosomes in Lepidoptera despite high rates of local genome rearrangements. Proc Natl Acad Sci USA 2010, 107:7680-7685.

76. Sane SP, Dieudonne A, Willis MA, Daniel TL: Antennal mechanosensors mediate flight control in moths. Science 2007, 315:863-866.

77. Yorozu S, Wong A, Fischer BJ, Dankert H, Kernan MJ, Kamikouchi A, Ito K, Anderson DJ: Distinct sensory representations of wind and near-field sound in the Drosophila brain. Nature 2009, 458:201-205.

78. Kamikouchi A, Inagaki HK, Effertz T, Hendrich O, Fiala A, Gopfert MC, Ito K: The neural basis of Drosophila gravity-sensing and hearing. Nature 2009, 458:165-171.

79. Merlin C, Gegear RJ, Reppert SM: Antennal circadian clocks coordinate sun compass orientation in migratory monarch butterflies. Science 2009, 325:1700-1704.
80. Poitout $S$, Buès $R$ : Elevage de chenilles de vingt-huit espèces de Lépidoptères Noctuidae et de deux espèces d'Arctiidae sur milieu artificiel simple. Particularités de l'élevage selon les espèces. Ann Zool Ecol anim 1974, 6:431-441.

81. Gouzy J, Carrere S, Schiex T: FrameDP: sensitive peptide detection on noisy matured sequences. Bioinformatics 2009, 25:670-671.

82. Conesa A, Gotz S, Garcia-Gomez JM, Terol J, Talon M, Robles M: Blast2GO: a universal tool for annotation, visualization and analysis in functional genomics research. Bioinformatics 2005, 21:3674-3676.

83. Bluthgen N, Brand K, Cajavec B, Swat M, Herzel H, Beule D: Biological profiling of gene groups utilizing Gene Ontology. Genome Inform 2005, 16:106-115.

84. Drysdale R: FlyBase: a database for the Drosophila research community. Methods Mol Biol 2008, 420:45-59.

85. Wang J, Xia Q, He X, Dai M, Ruan J, Chen J, Yu G, Yuan H, Hu Y, Li R, et al: SilkDB: a knowledgebase for silkworm biology and genomics. Nucleic Acids Res 2005, 33:D399-402.

86. Altschul SF, Madden TL, Schaffer AA, Zhang J, Zhang Z, Miller W, Lipman DJ: Gapped BLAST and PSI-BLAST: a new generation of protein database search programs. Nucleic Acids Res 1997, 25:3389-3402.

87. Larkin MA, Blackshields G, Brown NP, Chenna R, McGettigan PA, McWilliam H, Valentin F, Wallace IM, Wilm A, Lopez R, et al: Clustal W and Clustal X version 2.0. Bioinformatics 2007, 23:2947-2948.

88. Tamura K, Dudley J, Nei M, Kumar S: MEGA4: Molecular Evolutionary Genetics Analysis (MEGA) software version 4.0. Mol Biol Evol 2007, 24:1596-1599.

89. Pfaffl MW: A new mathematical model for relative quantification in realtime RT-PCR. Nucleic Acids Res 2001, 29:e45.

doi:10.1186/1471-2164-12-86

Cite this article as: Legeai et al:: An Expressed Sequence Tag collection from the male antennae of the Noctuid moth Spodoptera littoralis: a resource for olfactory and pheromone detection research. BMC Genomics 2011 12:86.

\section{Submit your next manuscript to BioMed Central and take full advantage of:}

- Convenient online submission

- Thorough peer review

- No space constraints or color figure charges

- Immediate publication on acceptance

- Inclusion in PubMed, CAS, Scopus and Google Scholar

- Research which is freely available for redistribution

Submit your manuscript at www.biomedcentral.com/submit
C Biomed Central 